Supporting information for

\title{
China Factor: Exploring the Byproduct and Host Metal Dynamics for Gallium-Aluminum in a Global Green Transition
}

Huiling Song ${ }^{\dagger, \ddagger}$, , Chang Wang ${ }^{\dagger, \ddagger}, *$, Burak Sen ${ }^{\S, \|, ~ G a n g ~ L i u}{ }^{\S, *}$

${ }^{\dagger}$ School of Business, Central South University, 410083 Changsha, China

* Institute of Metal Resources Strategy, Central South University, 410083 Changsha, China

$\S$ SDU Life Cycle Engineering, Department of Green Technology, University of Southern Denmark, 5230 Odense, Denmark

${ }^{\|}$Center for Research \& Development, and Applied Research, Faculty of Engineering, Sakarya University, 54050 Sakarya, Turkey

Email: changwang@csu.edu.cn, gli@igt.sdu.dk (*Corresponding author)

Phone: +4565509441

\section{Summary information:}

Number of pages: 51 pages

Figures: Figures S1-S19

Tables: Tables S1-S13 


\section{Contents}

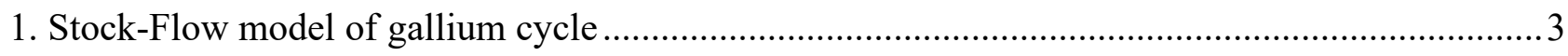

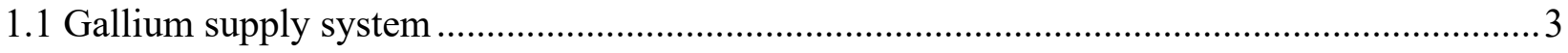

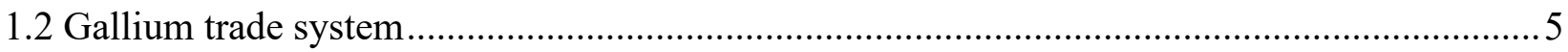

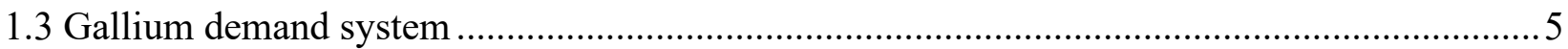

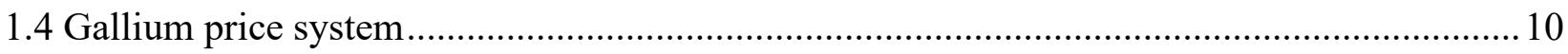

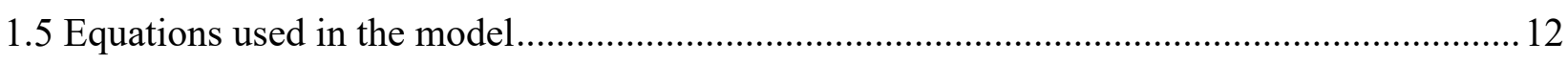

2. Data collection and parameters estimation in the model ................................................... 18

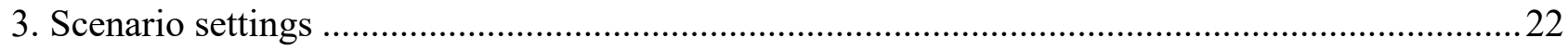

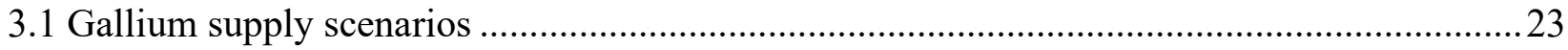

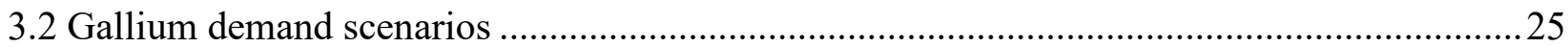

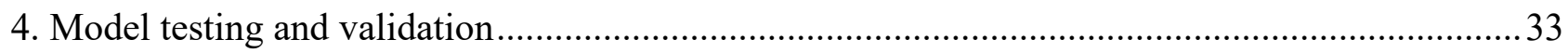

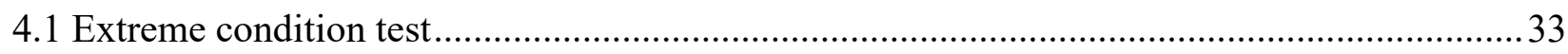

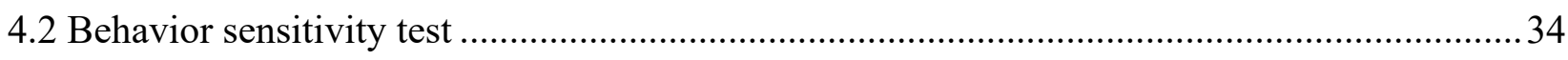

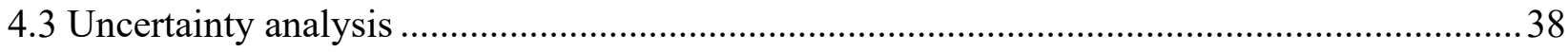

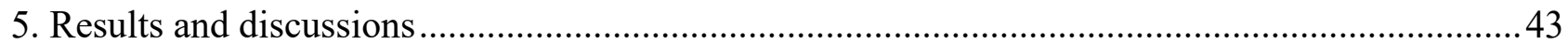

5.1 World and regional gallium supply and demand under different scenarios..........................43

5.2 Comparison between integrated SD model and MFA model for gallium cycle .................... 44

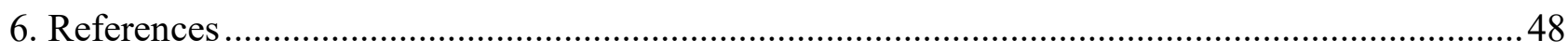




\section{Stock-Flow model of gallium cycle}

The stock-flow model of the gallium cycle can be described in four subsystems, including the gallium supply system, the gallium trade system, the gallium demand system, and the gallium price system, as shown in Figures S1-S4. The equations used in this model are summarized in section 1.5.

\subsection{Gallium supply system}

The gallium supply in each region, i.e. China, the United States (US), Japan, the European Union (EU), and the rest of the world (RoW), includes domestic supply and net import. Considering the China's dominant role in the global primary gallium production, the joint production relationship of gallium-aluminum is revealed in the China's gallium supply system, as shown in Figure S1. Gallium production from other raw material sources, such as zinc leach residue ( $<3 \%$ of production) and coal fly ash (currently not used), have not been included in this model. As there is less or no primary gallium production in the US, Japan, the EU, and the RoW, the primary gallium production in those regions is assumed to change with their production capacities, directly.

China's aluminum supply to the market consists of primary and secondary aluminum production. The primary aluminum supply is determined by bauxite supply, alumina import, and the production efficiency of alumina and aluminum (Eq. 1.1-1.6). The growth rate of bauxite production is changing to keep the market balance between aluminum supply and demand. The secondary aluminum supply is determined by scrap recycling efficiency and scrap collection including new aluminum scrap, old aluminum scrap, and imported aluminum scrap (Eq. 1.7-1.9). The future net import of bauxite, alumina, and aluminum in China is assumed to be the same as that in 2019. The amount of new aluminum scrap is influenced by the primary aluminum supply and the production rate of new aluminum scrap. The amount of old aluminum scrap is influenced by the aluminum output from the in-use stock and the old aluminum scrap collection rate. The aluminum in-use stock and the average lifetime of end-of-life aluminum products determine the aluminum output (Eq. 1.10-1.12). When the in-use aluminum products reach the end of their lifetime, they will be collected for recycling.

Final aluminum demand is influenced by the domestic aluminum demand and the demand losses due to price elasticity (Eq. 1.13-1.14). The price elasticity of demand characterizes the change in aluminum demand in response to the change in its price. Accordingly, the higher the value of elasticity, the more sensitive to the change of price the product or service is. ${ }^{1}$ To reflect the market conditions, the aluminum production cost is modeled to increase with the global average inflation rate $^{2}$. The impact of aluminum production cost on the aluminum price is estimated using the final aluminum 
production cost, the aluminum price, and the impact factor of aluminum production cost (Eq. 1.151.17). Moreover, the balance conditions of the aluminum supply and demand also affect the aluminum price by the sensitivity of aluminum price to the supply-demand balance (Eq. 1.18-1.19). Accordingly, the expected aluminum price can be calculated based on the impact of the aluminum supply-demand balance and the aluminum production cost (Eq. 1.20). Finally, the aluminum price will be estimated according to the time to adjust aluminum price, and the aluminum price growth determined by the expected aluminum price (Eq. 1.21-1.22).

The primary gallium production in China is determined by the primary gallium supply potential and the supply gap to meet global gallium demand (Eq. 1.23-1.24). Here, we have incorporated the model of byproduct availability curves developed by Frenzel et al. ${ }^{3}$ to quantify the gallium supply potential in China, which can be derived from bauxite production, mass fraction in bauxite, and gallium recovery rate from bauxite (Eq. 1.25). According to Frenzel et al., the cut-off gallium concentration can be derived from the estimated gallium price in our model. The marginal profit of gallium production in China was assumed to be 5\% based on the development of China's metal extraction and production industry ${ }^{4}$. Then the recovery rate of gallium from bauxite can be estimated based on the dynamical cut-off gallium concentration (Eq. 1.26-1.28). In addition, not all bauxite minerals are suitable for gallium extraction, and the additional gallium extraction processing could disturb the closed-loop recycling process of the Bayer liquor in the alumina production ${ }^{5}$. Thus, the share of bauxite used for gallium extraction is also considered to be an impact factor for gallium supply potential in our model.

As shown in Figure S1, the gallium supply in the US, EU, Japan and RoW includes primary gallium production, secondary gallium supply, and gallium net import (Eq. 1.29-1.32). The future primary gallium production in each region is assumed to reach its capacity in 2050 by following Scurve functions. The secondary gallium supply includes new scrap recycling and old scrap recycling (Eq. 1.33). The representative model for the secondary gallium production in one region is shown in Figure S2, and it has been applied to each studied region. The generations of the new gallium scrap in production and fabrication phases and the old gallium scrap from the end-of-life products can be seen in Figure S3. The new gallium scrap generation is mainly dependent on the yield or loss rate of the production and fabrication of intermediate gallium compounds. The new gallium scrap recycling is determined by the amount of scrap generation in the production and fabrication phases and the scrap recycling rate (Eq. 1.34-1.56). The old scrap generation and recycling rate determine the old gallium scrap recycling (Eq. 1.57). To estimate the quantity of old gallium scrap generated in different 
applications, this research has used the double-parameter Weibull distribution to model the gallium products lifespan.

\subsection{Gallium trade system}

The trade system links the gallium supply systems of the five world regions, as shown with red arrows in Figure S1. The dynamic feedback between the gallium trade and the gallium supply gap is incorporated in the SD model. The regional gallium trade is assumed to be changing according to the varying supply gap of gallium. Specifically, on the premise of meeting the domestic gallium demand, China will export excess gallium to other regions (Eq. 1.58-1.60). The future gallium export structure in China is determined by the gallium supply gaps in the other four regions (Eq. 1.61-1.69). The volumes of future gallium trade between those four regions are assumed to be the same level as that in 2019 given that no shortage occurs. Otherwise, they will decrease their gallium exports to other regions according to the gallium supply gap (Eq. 1.70-1.78).

\subsection{Gallium demand system}

The representative model for the gallium demand system in one region is shown in Figure S3, and it has been applied to the studied five regions. The gallium-containing applications that are considered in this study include light-emitting diodes (LEDs), integrated circuits (ICs), copper indium gallium diselenide (CIGS), and neodymium iron boron $(\mathrm{NdFeB})$ permanent magnets. The gallium demand in different phases, i.e. from production and fabrication through final use, has been estimated in the model.

\subsubsection{Gallium demand for LEDs}

The gallium demand for LEDs is determined by the LEDs market in each region. The LEDs market growth is driven by regional population growth and the penetration rate of LED lighting (Eq. 1.79). The penetration rate for each region is assumed to follow a logistic curve, and the future regional population growth is from the United Nations. ${ }^{6}$ GaAs-based LED, GaP based LED and GaNbased LED have been assumed to share the entire LED lighting market. In the final use phase, the gallium demand for the three LED types is influenced by their market, device thickness, deposition layer, and gallium intensity in each LED type (Eq. 1.80-1.82). In the fabrication phase, the parameters such as LED device area, LED fabrication loss rate, and substrate thickness determine the gallium demand for the GaAs/GaP based LED (Eq. 1.83-1.84); The deposition layer of LED, the LED fabrication loss rate, and the gallium demand for GaN-based LED into final-use determine the gallium 
demand for GaN-based LED (Eq. 1.85). In the production phase, the gallium demand is determined by the production yield of intermediate gallium compound/wafer and the gallium demand for the GaAs/GaP/GaN-based LED fabrication (Eq. 1.86-1.88).

\subsubsection{Gallium demand for ICs}

The gallium demand for ICs is from mobile phones and other wireless communication devices, such as laptops, tablet computers, and wireless infrastructure. ${ }^{7}$ A stock-driven model is developed for regional mobile phone sales, which determines the regional GaAs IC device areas in mobile phones with the area of GaAs chips per phone. According to Løvik et al., ${ }^{7}$ the GaAs IC market for other applications is assumed to be $82 \%$ of the GaAs IC market for mobile phones. The total area of GaAs IC device is the summary of the regional mobile phone market and other IC applications market (Eq. 1.89). Gallium demand for ICs into the final-use phase is determined by GaAs IC device area, gallium intensity, and thickness of IC chips (Eq. 1.90). Accordingly, the gallium demand for GaAs IC in the fabrication phase can be calculated from the gallium demand for ICs into final use, the fabrication loss rate, and the thickness of substrate or IC chips (Eq. 1.91). The gallium demand for GaAs IC in the production phase is influenced by the yield of GaAs substrate production and the gallium demand for GaAs IC fabrication (Eq. 1.92).

\subsubsection{Gallium demand for CIGS}

Gallium required for CIGS thin-film technology is driven by annual solar photovoltaic (PV) installed capacity and market share of CIGS in solar PV power (Eq. 1.93). The regional solar PV capacity installed annually is calculated by a stock-driven model based on the projected cumulative solar PV installed capacity from International Energy Agency (IEA) scenarios ${ }^{8}$. The factors that impact the gallium demand for CIGS into the final-use phase are the annual CIGS PV installed capacity and gallium intensity in CIGS (Eq. 1.94). The CIGS fabrication loss rate, the deposition yield, as well as the gallium demand for CIGS into final use, determine the gallium demand for CIGS in the fabrication phase (Eq. 1.95). The yield of CIGS production is needed to obtain the gallium demand for CIGS in the production phase (Eq. 1.96).

\subsubsection{Gallium demand for $\mathrm{NdFeB}$ magnet}

Gallium as an alloying element in $\mathrm{NdFeB}$ permanent magnets is used in electric vehicles (EV) motors, wind turbines, and other applications such as digital video discs for computers, speakers, and headsets for audio systems. Different EV types, including battery electric vehicles (BEV), and plugin hybrid electric vehicles (PHEV), are considered in the model. The share of BEV in the EV market 
is assumed to reach $90 \%$ in 2050 following a logistic function based on the historical market, and the share of PHEV will decrease to $10 \%$, correspondingly. The EV sales are determined by regional passenger car sales, obtained from a stock-driven model, and the EV market share in each region (Eq. 1.97-1.99). The gallium demand for EV into the final use phase is derived from EV sales and the gallium intensity of the EV (Eq. 1.100-1.102). The fabrication and production yields of $\mathrm{NdFeB}$ magnets influence the gallium demand for EV in the fabrication and production phases, respectively (Eq. 1.103-1.104).

The gallium demand for $\mathrm{NdFeB}$ magnets into wind power in each region is driven by the regional installed capacity of direct-drive wind turbines, the share of gallium-containing $\mathrm{NdFeB}$ magnets used in those turbines, and the gallium intensity of wind turbines (Eq. 1.105). The wind power installed capacity and the market share of direct drive wind turbines determine the installed capacity of directdrive wind turbines (Eq. 1.106). The annual wind power installed capacity is derived from the stockdriven model. Like the case for $\mathrm{EV}$, the fabrication and production yields of $\mathrm{NdFeB}$ magnets influence the gallium demand for wind turbines in the fabrication and production phases (Eq. 1.107-1.108).

The factors that affect the gallium demand for NdFeB magnets in other applications include the following variables: the demand for $\mathrm{NdFeB}$ magnets in other applications, the gallium intensity in these $\mathrm{NdFeB}$ magnets, and the share of $\mathrm{NdFeB}$ magnets using gallium (Eq. 1.109). According to the references Løvik et al. ${ }^{7}$ and Habib et al. ${ }^{9}$, the $\mathrm{NdFeB}$ demand for other applications will grow driven by the regional population growth. The fabrication and production yields of $\mathrm{NdFeB}$ magnets also influence the gallium demand for the $\mathrm{NdFeB}$ magnet fabrication and production in other applications (Eq. 1.110-1.111).

\subsubsection{Total gallium demand}

The total gallium demand for each region is the summary of gallium demand for LEDs, ICs, $\mathrm{NdFeB}$ magnets, and CIGS in the production phase (Eq. 1.112). As the gallium demand is changing in response to the changes in its price, an increase in the gallium price could result in a loss of gallium demand due to the price elasticity of gallium (Eq. 1.113). Thus, the final gallium demand is estimated by the total gallium demand and the gallium demand losses due to the price elasticity (Eq. 1.114). 


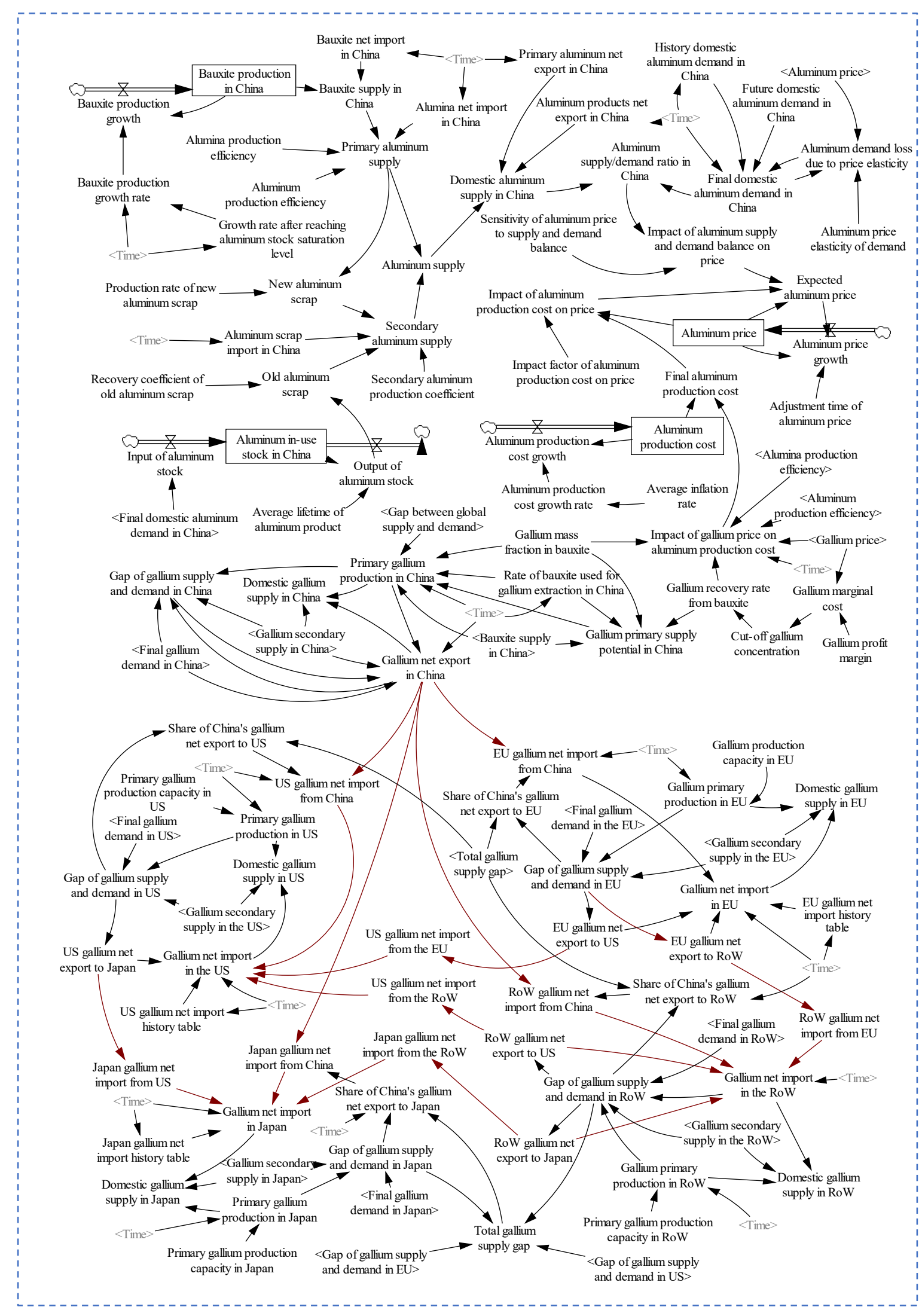

Figure S1. System dynamics model of gallium supply and trade system in the five world regions. The red lines with arrows represent the trade flows between the studied five world regions. 


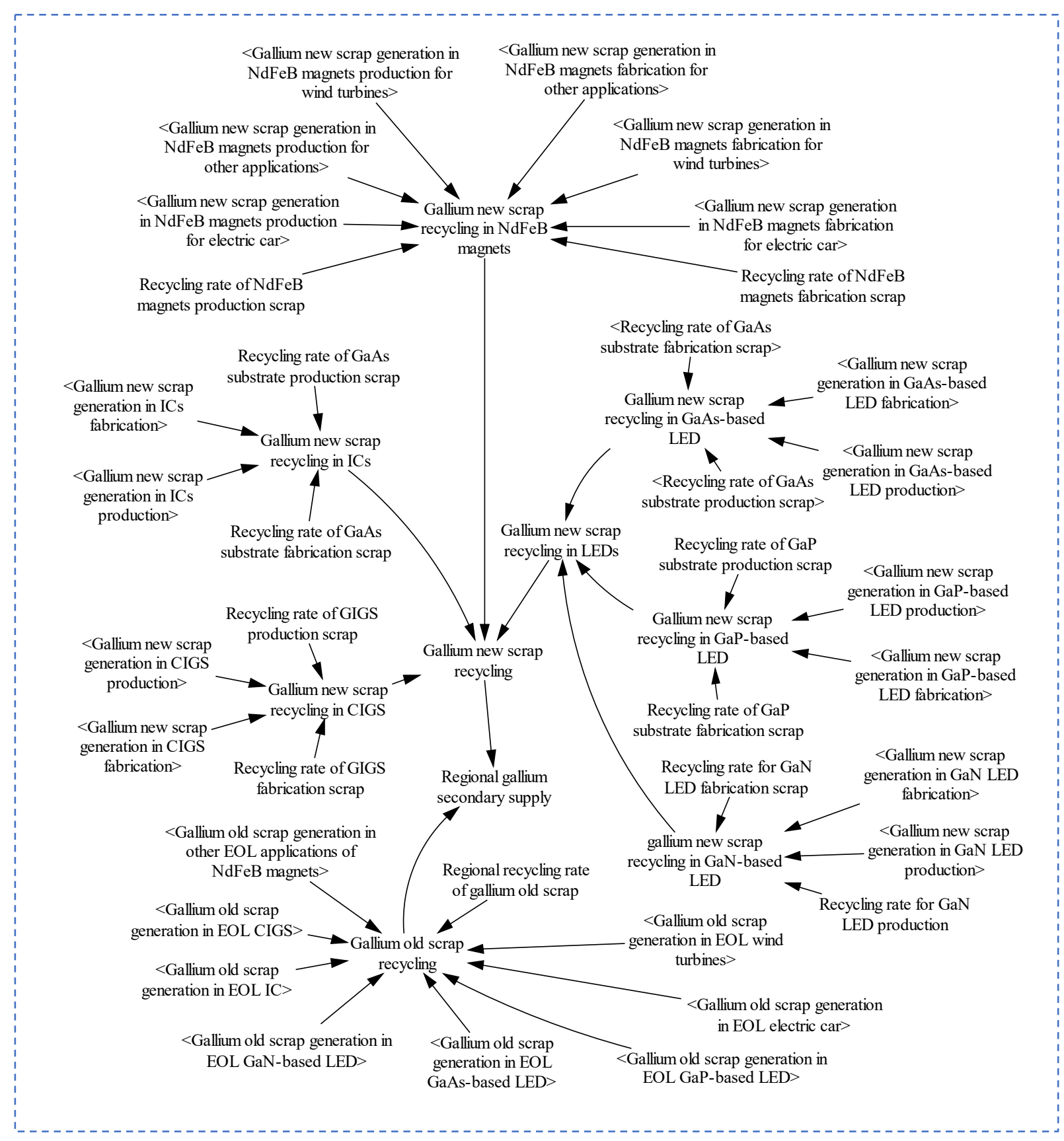

Figure S2. System dynamics model of gallium secondary supply in one region. 
(1) LEDs
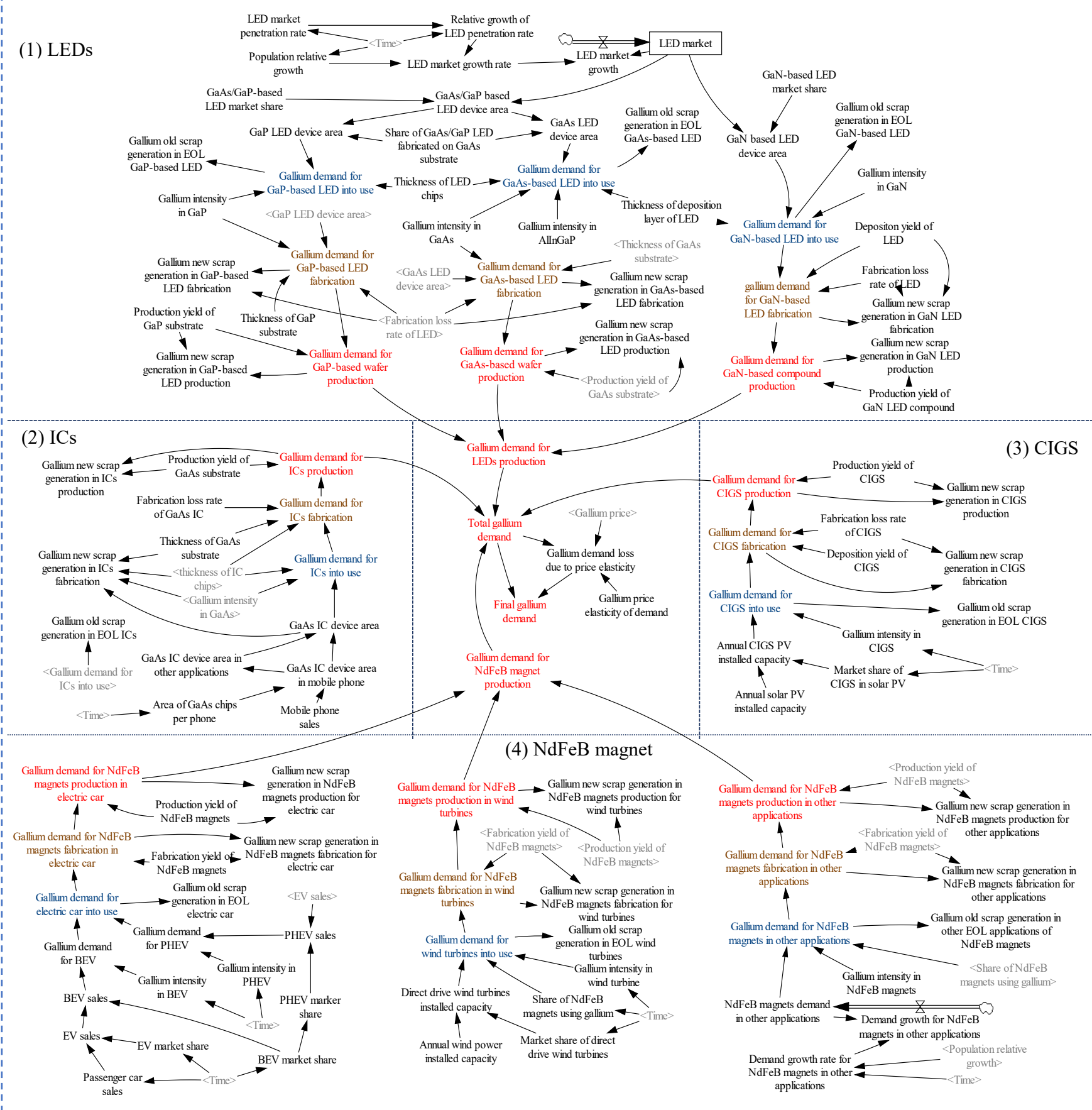

Figure S3. System dynamics model of regional gallium demand system. The parameters with blue, yellow, and red color represent the gallium demand in the final use phase, fabrication phase and wafer production phase, respectively.

\subsection{Gallium price system}

The gallium price system is shown in Figure S4. The market price of a unit of commodity, in general, will not drop below the production cost of a unit of the given commodity. Referring to the 
research conducted on indium ${ }^{1}$ and the technological innovation on gallium production, the gallium production cost is modeled in such a manner that it increases with the global average inflation rate to reflect the market conditions ${ }^{2}$ (Eq. 1.115-1.116). The influence of gallium production cost on price is estimated by the variables such as the gallium production cost, the gallium price, and the impact factor of gallium production cost on price (Eq. 1.117). Moreover, the balance conditions of gallium supply and demand also affect the gallium price by the sensitivity of gallium price to the supply-demand balance (Eq. 1.118-1.121). Accordingly, the expected gallium price can be calculated based on the impacts of gallium supply-demand balance and gallium production cost on its price (Eq. 1.122). Finally, the gallium price will be estimated according to the time that it takes to adjust the gallium price, and the gallium price growth determined by the expected gallium price (Eq. 1.123). The impact of gallium price on aluminum production cost is also considered in this model, which is affected by the aluminum production efficiency, the alumina production efficiency, the gallium mass fraction in bauxite, the gallium price, and the gallium recovery rate from bauxite (Eq. 1.124). The gallium price could also influence the gallium recovery rate from bauxite and the final gallium demand, reflecting the feedback relationship between the supply, demand and price of gallium, as shown in Figures S1 and S3.

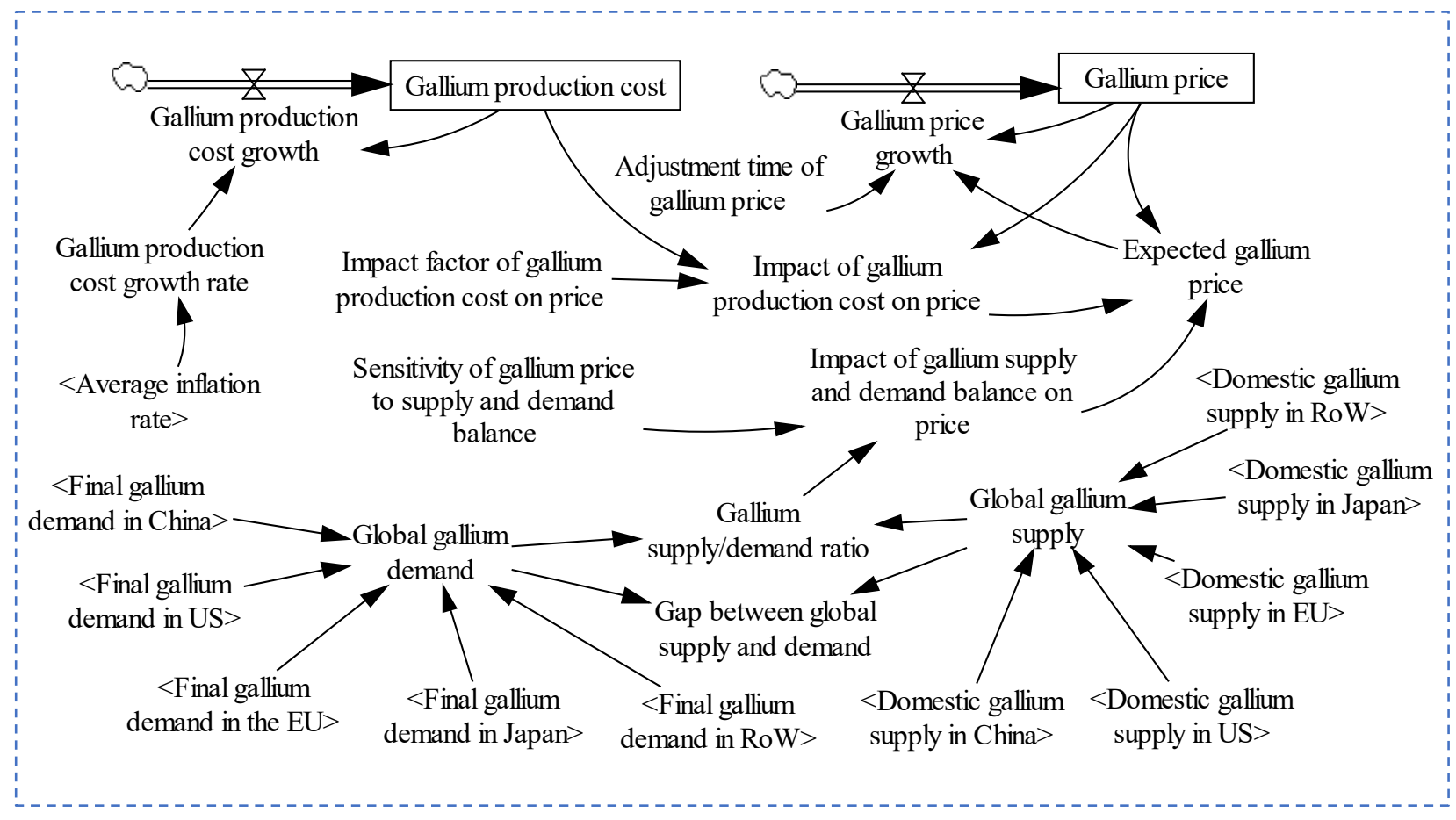

Figure S4. System dynamics model of the gallium price system 


\subsection{Equations used in the model}

Table S1. Description of equations in the SD model

\begin{tabular}{|c|c|c|c|}
\hline Number & Variable name & Units & Calculation formula \\
\hline$(1.1)$ & Bauxite production in China & tons/year & INTEG (Bauxite production growth, 9e+006) \\
\hline$(1.2)$ & Bauxite production growth & tons/year & $\begin{array}{l}\text { Bauxite production in China * Bauxite production } \\
\text { growth rate }\end{array}$ \\
\hline$(1.3)$ & Bauxite supply in China & tons/year & $\begin{array}{l}\text { Bauxite production in China + Bauxite net import in } \\
\text { China }\end{array}$ \\
\hline$(1.4)$ & Primary aluminum supply & tons/year & $\begin{array}{l}\text { (Bauxite supply in China * Alumina production } \\
\text { efficiency +Alumina net import) * Aluminum } \\
\text { production efficiency }\end{array}$ \\
\hline$(1.5)$ & Domestic Aluminum supply in China & tons/year & $\begin{array}{l}\text { Aluminum supply in China - Aluminum products net } \\
\text { export in China- Primary aluminum net export in China }\end{array}$ \\
\hline$(1.6)$ & Aluminum supply in China & tons/year & $\begin{array}{l}\text { Primary aluminum supply }+ \text { Secondary aluminum } \\
\text { supply }\end{array}$ \\
\hline$(1.7)$ & Secondary aluminum supply & tons/year & $\begin{array}{l}\text { (New aluminum scrap }+ \text { Old aluminum scrap }+ \text { Import } \\
\text { aluminum scrap) } * \text { Secondary aluminum production } \\
\text { coefficient }\end{array}$ \\
\hline$(1.8)$ & New aluminum scrap & tons/year & $\begin{array}{l}\text { Primary aluminum supply * Production rate of new } \\
\text { aluminum scrap }\end{array}$ \\
\hline$(1.9)$ & Old aluminum scrap & tons/year & $\begin{array}{l}\text { Output of aluminum stock } * \text { Old scrap recovery } \\
\text { coefficient }\end{array}$ \\
\hline$(1.10)$ & Aluminum output & tons/year & $\begin{array}{l}\text { Aluminum in use stock / Average lifetime of aluminum } \\
\text { product }\end{array}$ \\
\hline$(1.11)$ & Aluminum in use stock in China & tons/year & $\begin{array}{l}\text { INTEG (Input of aluminum stock - Output of aluminum } \\
\text { stock, } 3.12041 \mathrm{e}+007)\end{array}$ \\
\hline$(1.12)$ & Input of aluminum stock & tons/year & Final domestic aluminum demand in China \\
\hline$(1.13)$ & $\begin{array}{l}\text { Final domestic aluminum demand in } \\
\text { China }\end{array}$ & tons/year & $\begin{array}{l}\text { Domestic aluminum demand in China - Aluminum } \\
\text { demand loss due to price elasticity }\end{array}$ \\
\hline$(1.14)$ & $\begin{array}{l}\text { Aluminum demand loss due to price } \\
\text { elasticity }\end{array}$ & tons/year & $\begin{array}{l}\text {-Aluminum price elasticity of demand * (DELAY1 } \\
\text { (Aluminum price, 1) - Aluminum price) / DELAY1 } \\
\text { (Aluminum price, 1)* DELAY1 (Final aluminum } \\
\text { demand, 1) }\end{array}$ \\
\hline$(1.15)$ & Aluminum production cost & $\$ /$ ton & INTEG (Aluminum production cost growth, 1050) \\
\hline$(1.16)$ & Final aluminum production cost & $\$ /$ ton & $\begin{array}{l}\text { MAX }(0, \text { Aluminum production cost }- \text { Impact of } \\
\text { gallium price on aluminum production cost })\end{array}$ \\
\hline$(1.17)$ & $\begin{array}{l}\text { Impact of aluminum production cost } \\
\text { on price }\end{array}$ & 1 & $\begin{array}{l}\text { 1+Impact factor of aluminum production cost on price } * \\
\text { (Final aluminum production cost / Aluminum price }-1 \text { ) }\end{array}$ \\
\hline$(1.18)$ & $\begin{array}{l}\text { Aluminum supply/demand ratio in } \\
\text { China }\end{array}$ & 1 & $\begin{array}{l}\text { Domestic aluminum supply in China / Final domestic } \\
\text { aluminum demand in China }\end{array}$ \\
\hline$(1.19)$ & $\begin{array}{l}\text { Impact of aluminum supply and } \\
\text { demand balance on price }\end{array}$ & 1 & $\begin{array}{l}(1 / \text { Aluminum supply / demand ratio in China })^{\wedge} \\
\text { Sensitivity of aluminum price to supply and demand } \\
\text { balance }\end{array}$ \\
\hline$(1.20)$ & Expected aluminum price & $\$ /$ ton & $\begin{array}{l}\text { MAX (0, Aluminum price) } * \text { Impact of aluminum } \\
\text { production cost on price * Impact of aluminum supply } \\
\text { and demand balance on price }\end{array}$ \\
\hline$(1.21)$ & Aluminum price growth & $\$ /$ ton & $\begin{array}{l}\text { (Expected aluminum price - Aluminum price) / Adjust } \\
\text { time of aluminum price }\end{array}$ \\
\hline$(1.22)$ & Aluminum price & $\$ /$ ton & INTEG (Aluminum price growth, 1546) \\
\hline
\end{tabular}




\begin{tabular}{|c|c|c|c|}
\hline$(1.23)$ & Primary gallium production in China & tons/year & $\begin{array}{l}\text { IF THEN ELSE (time }<=2019, \text { Gallium mass fraction in } \\
\text { bauxite * } 0.2356 * \text { Bauxite supply in China * Rate of } \\
\text { bauxite used for gallium extraction in China } \\
\text {, MIN (Primary Gallium supply potential in China * } \\
0.9, \text { DELAY1(Primary gallium production in China, } 1) \\
\text { +DELAY1(Gap between global supply and demand,1)) }\end{array}$ \\
\hline$(1.24)$ & $\begin{array}{l}\text { Gap between global supply and } \\
\text { demand }\end{array}$ & tons/year & Global gallium demand - Global gallium supply \\
\hline$(1.25)$ & $\begin{array}{l}\text { Primary gallium supply potential in } \\
\text { China }\end{array}$ & tons/year & $\begin{array}{l}\text { Bauxite supply in China * Gallium mass fraction in } \\
\text { bauxite*Gallium recovery rate from bauxite*Rate of } \\
\text { bauxite used for gallium extraction in China }\end{array}$ \\
\hline$(1.26)$ & Gallium recovery rate from bauxite & 1 & $\begin{array}{l}(\text { MAX }(-0.0291488+54 * 0.8215 /(\text { Cut-off gallium } \\
\text { concentration } * 6.2) * 6.2 * \text { Cut-off gallium } \\
\text { concentration } / 54,0)+ \text { MAX }(-0.0390579+54 * 0.8215 \\
/(\text { Cut-off gallium concentration } * 3.5) * 3.5 * \text { Cut-off } \\
\text { gallium concentration } / 54,0)) / 2\end{array}$ \\
\hline$(1.27)$ & Cut-off gallium concentration & ppm & $(10823 / \text { marginal cost })^{\wedge}(1 / 0.65)$ \\
\hline$(1.28)$ & Gallium marginal cost & $\$ /$ ton & Gallium price / (1+Gallium margin profit) \\
\hline$(1.29)$ & Domestic gallium supply in US & tons/year & $\begin{array}{l}\text { Gallium secondary supply in US + Primary gallium } \\
\text { production in US + Gallium net import in US }\end{array}$ \\
\hline$(1.30)$ & Domestic gallium supply in EU & tons/year & $\begin{array}{l}\text { Gallium secondary supply in EU + Primary gallium } \\
\text { production in EU + Gallium net import in EU }\end{array}$ \\
\hline$(1.31)$ & Domestic gallium supply in Japan & tons/year & $\begin{array}{l}\text { Gallium secondary supply in Japan + Primary gallium } \\
\text { production in Japan + Gallium net import in Japan }\end{array}$ \\
\hline$(1.32)$ & Domestic gallium supply in RoW & tons/year & $\begin{array}{l}\text { Gallium secondary supply in RoW + Primary gallium } \\
\text { production in RoW + Gallium net import in RoW }\end{array}$ \\
\hline$(1.33)$ & Regional gallium secondary supply & tons/year & $\begin{array}{l}\text { Gallium new scrap recycling }+ \text { Gallium old scrap } \\
\text { recycling }\end{array}$ \\
\hline$(1.34)$ & $\begin{array}{l}\text { Gallium new scrap generation in ICs } \\
\text { production }\end{array}$ & tons/year & $\begin{array}{l}\text { Gallium demand for ICs production * }(1-\text { Yield of } \\
\text { GaAs substrate production })\end{array}$ \\
\hline$(1.35)$ & $\begin{array}{l}\text { Gallium new scrap generation in ICs } \\
\text { fabrication }\end{array}$ & tons/year & $\begin{array}{l}\text { GaAs IC device area } * \text { Intensity of gallium in GaAs* } \\
\text { (Thickness of GaAs substrate }+2 * 10^{\wedge}(-6)- \\
\text { Thickness of IC chips) }\end{array}$ \\
\hline$(1.36)$ & $\begin{array}{l}\text { Gallium new scrap generation in } \\
\text { CIGS production }\end{array}$ & tons/year & $\begin{array}{l}\text { Gallium demand for CIGS production * (1-Yield of } \\
\text { CIGS production) }\end{array}$ \\
\hline (1.37) & $\begin{array}{l}\text { Gallium new scrap generation in } \\
\text { CIGS fabrication }\end{array}$ & tons/year & $\begin{array}{l}\text { Gallium demand for CIGS fabrication * CIGS } \\
\text { fabrication loss rate }\end{array}$ \\
\hline (1.38) & $\begin{array}{l}\text { Gallium new scrap generation in } \\
\text { GaP-based LED production }\end{array}$ & tons/year & $\begin{array}{l}\text { Gallium demand for GaP-based wafer production * (1- } \\
\text { Yield of GaP substrate production) }\end{array}$ \\
\hline (1.39) & $\begin{array}{l}\text { Gallium new scrap generation in } \\
\text { GaP-based LED fabrication }\end{array}$ & tons/year & $\begin{array}{l}\text { Gallium demand for GaP-based LED fabrication * } \\
\text { LED fabrication loss rate }\end{array}$ \\
\hline$(1.40)$ & $\begin{array}{l}\text { Gallium new scrap generation in } \\
\text { GaAs-based LED production }\end{array}$ & tons/year & $\begin{array}{l}\text { Gallium demand for GaAs-based wafer production * (1- } \\
\text { Yield of GaAs substrate production) }\end{array}$ \\
\hline$(1.41)$ & $\begin{array}{l}\text { Gallium new scrap generation in } \\
\text { GaAs-based LED fabrication }\end{array}$ & tons/year & $\begin{array}{l}\text { Gallium demand for GaAs-based LED fabrication * } \\
\text { LED fabrication loss rate }\end{array}$ \\
\hline$(1.42)$ & $\begin{array}{l}\text { Gallium new scrap generation in } \\
\text { GaN LED production }\end{array}$ & tons/year & $\begin{array}{l}\text { Gallium demand for GaN-based compound production } \\
* \text { (1-Yield of GaN LED compound production) }\end{array}$ \\
\hline
\end{tabular}




\begin{tabular}{|c|c|c|c|}
\hline$(1.43)$ & $\begin{array}{l}\text { Gallium new scrap generation in } \\
\text { GaN LED fabrication }\end{array}$ & tons/year & $\begin{array}{l}\text { Gallium demand for GaN-based LED fabrication * }(1- \\
(1-\text { LED fabrication loss rate }) * \text { deposition yield of LED) }\end{array}$ \\
\hline$(1.44)$ & $\begin{array}{l}\text { Gallium new scrap generation in } \\
\text { NdFeB magnets production for } \\
\text { electric car }\end{array}$ & tons/year & $\begin{array}{l}\text { Gallium demand for NdFeB magnets production in } \\
\text { electric car * (1-Production yield in NdFeB magnets) }\end{array}$ \\
\hline$(1.45)$ & $\begin{array}{l}\text { Gallium new scrap generation in } \\
\text { NdFeB magnets fabrication for } \\
\text { electric car }\end{array}$ & tons/year & $\begin{array}{l}\text { Gallium demand for NdFeB magnets fabrication in } \\
\text { electric car * (1-Fabrication yield in NdFeB magnets) }\end{array}$ \\
\hline$(1.46)$ & $\begin{array}{l}\text { Gallium new scrap generation in } \\
\text { NdFeB magnets production for wind } \\
\text { turbines }\end{array}$ & tons/year & $\begin{array}{l}\text { Gallium demand for NdFeB magnets production in } \\
\text { wind turbines * (1-Production yield in NdFeB magnets) }\end{array}$ \\
\hline$(1.47)$ & $\begin{array}{l}\text { Gallium new scrap generation in } \\
\text { NdFeB magnets fabrication for wind } \\
\text { turbines }\end{array}$ & tons/year & $\begin{array}{l}\text { Gallium demand for NdFeB magnets fabrication in } \\
\text { wind turbines * (1-Fabrication yield in NdFeB magnets) }\end{array}$ \\
\hline$(1.48)$ & \begin{tabular}{|l|} 
Gallium new scrap generation in \\
NdFeB magnets production for other \\
applications
\end{tabular} & tons/year & $\begin{array}{l}\text { Gallium demand for NdFeB magnets production in } \\
\text { other applications * (1-Production yield in NdFeB } \\
\text { magnets) }\end{array}$ \\
\hline$(1.49)$ & $\begin{array}{l}\text { Gallium new scrap generation in } \\
\text { NdFeB magnets fabrication for other } \\
\text { applications }\end{array}$ & tons/year & $\begin{array}{l}\text { Gallium demand for NdFeB magnets fabrication in } \\
\text { other applications * (1-Fabrication yield in NdFeB } \\
\text { magnets) }\end{array}$ \\
\hline$(1.50)$ & $\begin{array}{l}\text { Gallium new scrap recycling in } \\
\text { NdFeB magnets }\end{array}$ & tons/year & $\begin{array}{l}\text { (Gallium new scrap generation in NdFeB magnets } \\
\text { fabrication for wind turbines + Gallium new scrap } \\
\text { generation in NdFeB magnets fabrication for other } \\
\text { applications }+ \text { Gallium new scrap generation in NdFeB } \\
\text { magnets fabrication for electric car) * Recycling rate of } \\
\text { NdFeB magnets fabrication scrap + (Gallium new scrap } \\
\text { generation in NdFeB magnets production for wind } \\
\text { turbines + Gallium new scrap generation in NdFeB } \\
\text { magnets production for other applications + Gallium } \\
\text { new scrap generation in NdFeB magnets production for } \\
\text { electric car) *Recycling rate of NdFeB magnets } \\
\text { production scrap }\end{array}$ \\
\hline$(1.51)$ & Gallium new scrap recycling in ICs & tons/year & $\begin{array}{l}\text { Gallium new scrap generation in ICs fabrication * } \\
\text { Recycling rate of GaAs substrate fabrication scrap }+ \\
\text { Gallium new scrap generation in ICs production * } \\
\text { Recycling rate of GaAs substrate production scrap }\end{array}$ \\
\hline$(1.52)$ & Gallium new scrap recycling in CIGS & tons/year & $\begin{array}{l}\text { Gallium new scrap generation in CIGS fabrication* } \\
\text { Recycling rate of GIGS fabrication scrap + Gallium } \\
\text { new scrap generation in CIGS production * Recycling } \\
\text { rate of GIGS production scrap }\end{array}$ \\
\hline$(1.53)$ & Gallium new scrap recycling in LEDs & tons/year & $\begin{array}{l}\text { Gallium new scrap recycling in GaAs-based LED + } \\
\text { Gallium new scrap recycling in GaN-based LED + } \\
\text { Gallium new scrap recycling in GaP-based LED }\end{array}$ \\
\hline$(1.54)$ & $\begin{array}{l}\text { Gallium new scrap recycling in } \\
\text { GaAs-based LED }\end{array}$ & tons/year & $\begin{array}{l}\text { Gallium new scrap generation in GaAs-based LED } \\
\text { fabrication * Recycling rate of GaAs substrate } \\
\text { fabrication scrap + Gallium new scrap generation in } \\
\text { GaAs-based LED production * Recycling rate of GaAs } \\
\text { substrate production scrap }\end{array}$ \\
\hline$(1.55)$ & $\begin{array}{l}\text { Gallium new scrap recycling in GaP- } \\
\text { based LED }\end{array}$ & tons/year & $\begin{array}{l}\text { Gallium new scrap generation in GaP-based LED } \\
\text { production * Recycling rate of GaP substrate production } \\
\text { scrap + Gallium new scrap generation in GaP-based } \\
\text { LED fabrication * Recycling rate of GaP substrate } \\
\text { fabrication scrap }\end{array}$ \\
\hline
\end{tabular}




\begin{tabular}{|c|c|c|c|}
\hline$(1.56)$ & $\begin{array}{l}\text { Gallium new scrap recycling in } \mathrm{GaN}- \\
\text { based LED }\end{array}$ & tons/year & $\begin{array}{l}\text { Gallium new scrap generation in GaN LED fabrication } \\
\text { * Recycling rate for GaN LED fabrication scrap }+ \\
\text { Gallium new scrap generation in GaN LED production } \\
\text { * Recycling rate for GaN LED production }\end{array}$ \\
\hline$(1.57)$ & Gallium old scrap recycling & tons/year & $\begin{array}{l}\text { (Gallium old scrap generation in EOL CIGS + Gallium } \\
\text { old scrap generation in EOL wind turbines + Gallium } \\
\text { old scrap generation in EOL electric car + Gallium old } \\
\text { scrap generation in EOL GaP-based LED + Gallium old } \\
\text { scrap generation in EOL GaAs-based LED + Gallium } \\
\text { old scrap generation in EOL GaN-based LED + Gallium } \\
\text { old scrap generation in EOL ICs + Gallium old scrap } \\
\text { generation in other EOL applications of NdFeB } \\
\text { magnets) * Regional gallium old scrap recycle rate }\end{array}$ \\
\hline$(1.58)$ & $\begin{array}{l}\text { Gap of gallium supply and demand in } \\
\text { China }\end{array}$ & tons/year & $\begin{array}{l}\text { Primary gallium production in China }+ \text { Gallium } \\
\text { secondary supply in China }- \text { Final gallium demand in } \\
\text { China - DELAY } 1 \text { (Gallium net export in China, 1) }\end{array}$ \\
\hline$(1.59)$ & Gallium net export in China & tons/year & $\begin{array}{l}\text { IF THEN ELSE (Time }<=2019 \text {, IF THEN ELSE (Gap of } \\
\text { gallium supply and demand in China }>=0 \text {, Primary } \\
\text { gallium production in China* } 0.4 \text {, MAX ( } 0 \text {, Primary } \\
\text { gallium production in China* } 0.4+\text { Gap of gallium supply } \\
\text { and demand in China)), Primary gallium production in } \\
\text { China + Gallium secondary supply in China - Final } \\
\text { gallium demand in China) }\end{array}$ \\
\hline$(1.60)$ & Domestic gallium supply in China & tons/year & $\begin{array}{l}\text { Primary gallium production in China + Gallium } \\
\text { secondary supply in China - Gallium net export in } \\
\text { China }\end{array}$ \\
\hline$(1.61)$ & Total gallium supply gap & tons/year & $\begin{array}{l}\text { MIN (0, Gap of gallium supply and demand in } \\
\text { EU)+MIN( } 0 \text {, Gap of gallium supply and demand in } \\
\text { Japan)+MIN(0, Gap of gallium supply and demand in } \\
\text { RoW)+MIN( } 0 \text {, Gap of gallium supply and demand in } \\
\text { US) }\end{array}$ \\
\hline$(1.62)$ & $\begin{array}{l}\text { Gap of gallium supply and demand in } \\
\text { EU }\end{array}$ & tons/year & $\begin{array}{l}\text { Gallium primary production in EU + Gallium secondary } \\
\text { supply in EU - Final gallium demand in the EU }\end{array}$ \\
\hline$(1.63)$ & $\begin{array}{l}\text { Gap of gallium supply and demand in } \\
\text { Japan }\end{array}$ & tons/year & $\begin{array}{l}\text { Gallium secondary supply in Japan + Primary gallium } \\
\text { production in Japan - Final gallium demand in Japan }\end{array}$ \\
\hline$(1.64)$ & $\begin{array}{l}\text { Gap of gallium supply and demand in } \\
\text { RoW }\end{array}$ & tons/year & $\begin{array}{l}\text { DELAY1 (Gallium net import in the RoW, 1) + Gallium } \\
\text { primary production in RoW + Gallium secondary } \\
\text { supply in the RoW - Final gallium demand in RoW }\end{array}$ \\
\hline$(1.65)$ & $\begin{array}{l}\text { Gap of gallium supply and demand in } \\
\text { US }\end{array}$ & tons/year & $\begin{array}{l}\text { Gallium secondary supply in the US + Primary gallium } \\
\text { production in US - Final gallium demand in US }\end{array}$ \\
\hline$(1.66)$ & $\begin{array}{l}\text { Share of China's gallium net export to } \\
\text { Japan }\end{array}$ & 1 & $\begin{array}{l}\text { IF THEN ELSE (Time< }<=2019,0.4 \text {, Gap of gallium } \\
\text { supply and demand in Japan / Total gallium supply gap) }\end{array}$ \\
\hline$(1.67)$ & $\begin{array}{l}\text { Share of China's gallium net export to } \\
\text { US }\end{array}$ & 1 & $\begin{array}{l}\text { IF THEN ELSE (Time }<=2019,0.2 \text {, Gap of gallium } \\
\text { supply and demand in US / Total gallium supply gap) }\end{array}$ \\
\hline$(1.68)$ & $\begin{array}{l}\text { Share of China's gallium net export to } \\
\text { EU }\end{array}$ & 1 & $\begin{array}{l}\text { IF THEN ELSE (Time }<=2019,0.2 \text {, Gap of gallium } \\
\text { supply and demand in EU / Total gallium supply gap) }\end{array}$ \\
\hline (1.69) & $\begin{array}{l}\text { Share of China's gallium net export to } \\
\text { RoW }\end{array}$ & 1 & $\begin{array}{l}\text { IF THEN ELSE (Time }<=2019,0.2 \text {, Gap of gallium } \\
\text { supply and demand in RoW / Total gallium supply gap) }\end{array}$ \\
\hline$(1.70)$ & Gallium net import in US & tons/year & $\begin{array}{l}\text { IF THEN ELSE (Time }<2019 \text {, US gallium net import } \\
\text { history table, US gallium net import from CN + US } \\
\text { gallium net import from EU + US gallium net import } \\
\text { from RoW - US gallium net export to Japan) }\end{array}$ \\
\hline$(1.71)$ & US gallium net export to Japan & tons/year & $\begin{array}{l}\text { IF THEN ELSE (Gap of gallium supply and demand in } \\
\text { US }>=0,5 \text {, MAX ( } 0 \text {, Gap of gallium supply and } \\
\text { demand in US }+5) \text { ) }\end{array}$ \\
\hline
\end{tabular}




\begin{tabular}{|c|c|c|c|}
\hline$(1.72)$ & Gallium net import in EU & tons/year & $\begin{array}{l}\text { IF THEN ELSE (Time }<=2019 \text {, EU gallium net import } \\
\text { history table, MAX (0, EU gallium net import from CN } \\
- \text { EU gallium net export to US - EU gallium net export } \\
\text { to RoW)) }\end{array}$ \\
\hline (1.73) & EU gallium net export to US & tons/year & $\begin{array}{l}\text { IF THEN ELSE (Gap of gallium supply and demand in } \\
\text { EU }>=0,2 \text {, MAX }(0, \text { Gap of gallium supply and } \\
\text { demand in EU * } 0.65+2) \text { ) }\end{array}$ \\
\hline (1.74) & EU gallium net export to RoW & tons/year & $\begin{array}{l}\text { IF THEN ELSE (Gap of gallium supply and demand in } \\
\text { EU }>=0,1.2, \operatorname{MAX}(0, \text { Gap of gallium supply and } \\
\text { demand in EU } * 0.35+1.2) \text { ) }\end{array}$ \\
\hline$(1.75)$ & Gallium net import in Japan & tons/year & $\begin{array}{l}\text { IF THEN ELSE (Time }<=2019 \text {, Japan gallium net } \\
\text { import history table, Japan gallium net import from CN } \\
+ \text { Japan gallium net import from US + Japan gallium net } \\
\text { import from RoW) }\end{array}$ \\
\hline (1.76) & Gallium net import in RoW & tons/year & $\begin{array}{l}\text { IF THEN ELSE (Time }<=2019, \text { RoW gallium net import } \\
\text { history table, RoW gallium net import from CN }+ \text { RoW } \\
\text { gallium net import from US + RoW gallium net import } \\
\text { from Japan+ RoW gallium net import from EU)) }\end{array}$ \\
\hline$(1.77)$ & Row gallium net export to Japan & tons/year & $\begin{array}{l}\text { IF THEN ELSE (Gap of gallium supply and demand in } \\
\text { RoW }>=0,19, \text { MAX }(0, \text { Gap of gallium supply and } \\
\text { demand in RoW } * 0.73+19))\end{array}$ \\
\hline$(1.78)$ & Row gallium net export to US & tons/year & $\begin{array}{l}\text { IF THEN ELSE (Gap of gallium supply and demand in } \\
\text { RoW }>=0,7, \text { MAX }(0, \text { Gap of gallium supply and } \\
\text { demand in RoW } * 0.27+7) \text { ) } \\
\end{array}$ \\
\hline$(1.79)$ & LED market growth rate & 1 & $\begin{array}{l}\text { (Relative growth of LED penetration rate * Population } \\
\text { relative growth }-1 \text { ) }\end{array}$ \\
\hline$(1.80)$ & $\begin{array}{l}\text { Gallium demand for GaP based LED } \\
\text { into use }\end{array}$ & tons/year & $\begin{array}{l}\text { GaP based LED device area * Gallium intensity in GaP } \\
\text { * Thickness of LED chips }\end{array}$ \\
\hline$(1.81)$ & $\begin{array}{l}\text { Gallium demand for GaAs based } \\
\text { LED into use }\end{array}$ & tons/year & $\begin{array}{l}\text { GaAs LED device area * ((Thickness of LED chips - } \\
\text { Thickness of deposition layer of LED) * Gallium } \\
\text { intensity in GaAs + Thickness of deposition layer of } \\
\text { LED * Gallium intensity in AlInGaP) }\end{array}$ \\
\hline$(1.82)$ & $\begin{array}{l}\text { Gallium demand for GaN based LED } \\
\text { into use }\end{array}$ & tons/year & $\begin{array}{l}\text { GaN based LED area * Gallium intensity in } \\
\text { GaN*Thickness of deposition layer of LED }\end{array}$ \\
\hline$(1.83)$ & $\begin{array}{l}\text { Gallium demand for GaP based LED } \\
\text { fabrication }\end{array}$ & tons/year & $\begin{array}{l}\text { GaP LED device area * Gallium intensity in } \mathrm{GaP}^{*} \\
\text { Thickness of GaP substrate / (1- Fabrication loss rate of } \\
\text { LED) }\end{array}$ \\
\hline$(1.84)$ & $\begin{array}{l}\text { Gallium demand for GaAs based } \\
\text { LED fabrication }\end{array}$ & tons/year & $\begin{array}{l}\text { GaAs LED device area * Gallium intensity in } \\
\text { GaAs*Thickness of GaAs substrate / (1- Fabrication } \\
\text { loss rate of LED) }\end{array}$ \\
\hline$(1.85)$ & $\begin{array}{l}\text { Gallium demand for GaN based LED } \\
\text { fabrication }\end{array}$ & tons/year & $\begin{array}{l}\text { Gallium demand for GaN-based LED into use / ( } 1 \text { - } \\
\text { Fabrication loss rate of LED) / Depositon yield of LED }\end{array}$ \\
\hline$(1.86)$ & $\begin{array}{l}\text { Gallium demand for GaP based wafer } \\
\text { production }\end{array}$ & tons/year & $\begin{array}{l}\text { Gallium demand for GaP based LED fabrication / Yield } \\
\text { of GaP substrate production LED }\end{array}$ \\
\hline$(1.87)$ & $\begin{array}{l}\text { Gallium demand for GaAs based } \\
\text { wafer production }\end{array}$ & tons/year & $\begin{array}{l}\text { Gallium demand for GaAs-based LED fabrication / } \\
\text { Yield of GaAs substrate production LED }\end{array}$ \\
\hline$(1.88)$ & $\begin{array}{l}\text { Gallium demand for } \mathrm{GaN} \text { based } \\
\text { compound production }\end{array}$ & tons/year & $\begin{array}{l}\text { Gallium demand for GaN based LED fabrication / Yield } \\
\text { of GaN based LED compound production LED }\end{array}$ \\
\hline
\end{tabular}




\begin{tabular}{|c|c|c|c|}
\hline$(1.89)$ & GaAs IC device area in mobile phone & $\mathrm{m}^{2}$ & Mobile phone sales * Area of GaAs chips per phone \\
\hline$(1.90)$ & Gallium demand for ICs into use & tons/year & $\begin{array}{l}\text { Gallium intensity in GaAs * GaAs IC device area * } \\
\text { Thickness of IC chips }\end{array}$ \\
\hline$(1.91)$ & $\begin{array}{l}\text { Gallium demand for ICs into } \\
\text { fabrication }\end{array}$ & tons/year & $\begin{array}{l}\text { Gallium demand for ICs into use / Thickness of IC } \\
\text { chips * Thickness of GaAs substrate / ( } 1 \text { - GaAs IC } \\
\text { fabrication loss rate) }\end{array}$ \\
\hline$(1.92)$ & $\begin{array}{l}\text { Gallium demand for ICs into } \\
\text { production }\end{array}$ & tons/year & $\begin{array}{l}\text { Gallium demand for ICs fabrication / Yield of GaAs } \\
\text { substrate production }\end{array}$ \\
\hline$(1.93)$ & $\begin{array}{l}\text { Annual CIGS solar PV installed } \\
\text { capacity }\end{array}$ & MW/year & $\begin{array}{l}\text { Annual solar PV installed capacity * Market share of } \\
\text { CIGS in solar PV power }\end{array}$ \\
\hline$(1.94)$ & Gallium demand for CIGS into use & tons/year & $\begin{array}{l}\text { Gallium intensity in CIGS * Annual CIGS PV installed } \\
\text { capacity }\end{array}$ \\
\hline$(1.95)$ & $\begin{array}{l}\text { Gallium demand for CIGS into } \\
\text { fabrication }\end{array}$ & tons/year & $\begin{array}{l}\text { Gallium demand for CIGS into use / (1-CIGS } \\
\text { fabrication loss rate) / Deposition yield CIGS }\end{array}$ \\
\hline$(1.96)$ & $\begin{array}{l}\text { Gallium demand for CIGS into } \\
\text { production }\end{array}$ & tons/year & $\begin{array}{l}\text { Gallium demand for CIGS fabrication / Yield of CIGS } \\
\text { production }\end{array}$ \\
\hline$(1.97)$ & EV sales & units/year & Passenger cars sales $*$ EV market share \\
\hline$(1.98)$ & BEV sales & units/year & EV sales * Market share of BEV \\
\hline$(1.99)$ & PHEV sales & units/year & EV sales * Market share of PHEV \\
\hline$(1.100)$ & Gallium demand for BEV & tons/year & BEV sales * Gallium intensity in BEV \\
\hline$(1.101)$ & Gallium demand for PHEV & tons/year & PHEV sales * Gallium intensity in PHEV \\
\hline$(1.102)$ & Gallium demand for EV into use & tons/year & Gallium demand for BEV + Gallium demand for PHEV \\
\hline$(1.103)$ & $\begin{array}{l}\text { Gallium demand for NdFeB magnets } \\
\text { fabrication in } \mathrm{EVS}\end{array}$ & tons/year & $\begin{array}{l}\text { Gallium demand for electric car into use / Fabrication } \\
\text { yield in NdFeB magnets }\end{array}$ \\
\hline$(1.104)$ & $\begin{array}{l}\text { Gallium demand for } \mathrm{NdFeB} \text { magnets } \\
\text { production in } \mathrm{EVs}\end{array}$ & tons/year & $\begin{array}{l}\text { Gallium demand for NdFeB magnets fabrication in } \\
\text { electric cars / Production yield in NdFeB magnets }\end{array}$ \\
\hline$(1.105)$ & $\begin{array}{l}\text { Gallium demand for wind turbines } \\
\text { into use }\end{array}$ & tons/year & $\begin{array}{l}\text { Gallium intensity in direct drive wind turbines } * \text { Annual } \\
\text { direct drive wind turbines installed capacity }\end{array}$ \\
\hline$(1.106)$ & $\begin{array}{l}\text { Annual direct drive wind turbines } \\
\text { installed capacity }\end{array}$ & MW/year & $\begin{array}{l}\text { Annual wind turbines installed capacity * Market share } \\
\text { of direct drive wind turbines in wind power }\end{array}$ \\
\hline$(1.107)$ & $\begin{array}{l}\text { Gallium demand for NdFeB magnets } \\
\text { fabrication in wind turbines }\end{array}$ & tons/year & $\begin{array}{l}\text { Gallium demand for wind turbines into use / Fabrication } \\
\text { yield in NdFeB magnets }\end{array}$ \\
\hline$(1.108)$ & $\begin{array}{l}\text { Gallium demand for NdFeB magnets } \\
\text { production in wind turbines }\end{array}$ & tons/year & $\begin{array}{l}\text { Gallium demand for } \mathrm{NdFeB} \text { magnets fabrication in } \\
\text { wind turbines / Production yield in NdFeB magnets }\end{array}$ \\
\hline$(1.109)$ & $\begin{array}{l}\text { Gallium demand for } \mathrm{NdFeB} \text { magnets } \\
\text { in other applications }\end{array}$ & tons/year & $\begin{array}{l}\text { NdFeB magnets demand in other applications * Gallium } \\
\text { intensity in NdFeB magnets * Share of NdFeB magnets } \\
\text { using gallium }\end{array}$ \\
\hline$(1.110)$ & $\begin{array}{l}\text { Gallium demand for NdFeB magnets } \\
\text { fabrication in other applications }\end{array}$ & tons/year & $\begin{array}{l}\text { Gallium demand for NdFeB magnets in other } \\
\text { applications / Fabrication yield in NdFeB magnets }\end{array}$ \\
\hline$(1.111)$ & $\begin{array}{l}\text { Gallium demand for NdFeB magnets } \\
\text { production in other applications }\end{array}$ & tons/year & $\begin{array}{l}\text { Gallium demand for NdFeB magnets fabrication in } \\
\text { other applications / Production yield in NdFeB magnets }\end{array}$ \\
\hline$(1.112)$ & Total gallium demand & tons/year & $\begin{array}{l}\text { gallium demand for ICs production }+ \text { gallium demand } \\
\text { for CIGS production }+ \text { Gallium demand for LEDs } \\
\text { production }+ \text { Gallium demand for ndfeb magnet } \\
\text { production }\end{array}$ \\
\hline
\end{tabular}




\begin{tabular}{|c|c|c|c|}
\hline$(1.113)$ & $\begin{array}{l}\text { Gallium demand loss due to price } \\
\text { elasticity }\end{array}$ & tons/year & $\begin{array}{l}\text { - Gallium price elasticity of demand * (DELAY1 } \\
\text { (Gallium price, } 1) \text { - Gallium price) / DELAY1 (Gallium } \\
\text { price, } 1) * \text { DELAY1 (Final gallium demand, } 1)\end{array}$ \\
\hline$(1.114)$ & Final gallium demand & tons/year & $\begin{array}{l}\text { Total gallium demand - Gallium demand loss due to } \\
\text { price elasticity }\end{array}$ \\
\hline$(1.115)$ & Gallium production cost growth rate & 1 & Average inflation rate $-2 \%$ \\
\hline$(1.116)$ & Gallium production cost & $\$ /$ ton & INTEG (Gallium production cost growth, 430000) \\
\hline$(1.117)$ & $\begin{array}{l}\text { Impact of gallium production cost on } \\
\text { price }\end{array}$ & 1 & $\begin{array}{l}\text { 1+Impact factor of gallium production cost on price * } \\
\text { (Gallium production cost / Gallium price }-1 \text { ) }\end{array}$ \\
\hline$(1.118)$ & $\begin{array}{l}\text { Impact of gallium supply and } \\
\text { demand balance on price }\end{array}$ & 1 & $\begin{array}{l}(1 / \text { Gallium supply / demand ratio })^{\wedge} \text { Sensitivity of } \\
\text { gallium price to supply and demand balance }\end{array}$ \\
\hline$(1.119)$ & Global gallium supply & tons/year & $\begin{array}{l}\text { Domestic gallium supply in China + Domestic gallium } \\
\text { supply in US + Domestic Gallium supply in EU + } \\
\text { Domestic gallium supply in Japan + Domestic gallium } \\
\text { supply in RoW }\end{array}$ \\
\hline$(1.120)$ & Global gallium demand & tons/year & $\begin{array}{l}\text { Final gallium demand in China + Final gallium demand } \\
\text { in US + Final gallium demand in EU + Final gallium } \\
\text { demand in Japan + Final gallium demand in RoW }\end{array}$ \\
\hline$(1.121)$ & Gallium supply/demand ratio & 1 & Global gallium supply / Global gallium demand \\
\hline$(1.122)$ & Expected gallium price & $\$ /$ ton & $\begin{array}{l}\text { MAX }(0, \text { Gallium price }) * \text { Impact of gallium } \\
\text { production cost on price * Impact of gallium supply and } \\
\text { demand balance on price }\end{array}$ \\
\hline$(1.123)$ & Gallium price & $\$ /$ ton & INTEG (Gallium price growth, 467000) \\
\hline$(1.124)$ & $\begin{array}{l}\text { Impact of gallium price on aluminum } \\
\text { production cost }\end{array}$ & 1 & $\begin{array}{l}\text { IF THEN ELSE (Time }<=2019,1 / \text { (Aluminum } \\
\text { production efficiency * Alumina production efficiency) } \\
* \text { Gallium mass fraction in bauxite * Gallium price * } \\
0.2356,1 / \text { (Aluminum production efficiency * Alumina } \\
\text { production efficiency) * Gallium mass fraction in } \\
\text { bauxite * Gallium price * Gallium recovery rate from } \\
\text { bauxite) }\end{array}$ \\
\hline
\end{tabular}

\section{Data collection and parameters estimation in the model}

The parameters used in the model are shown in Table S2. Most of the parameters are set based on relevant literature, but some parameters are calculated through the dynamic material flow analysis or assumed according to the related market conditions. Specifically, the mobile phone sales, passenger car sales, annual installed capacity of solar PV and wind power in each region are derived by a stockdriven model, which is used to estimate the required inflow (sales) from a predefined in-use stock. The calculation procedure consists of the following three steps:

Firstly, the in-use stocks of technologies or products are estimated. The future cumulative installed capacity (stock) of solar PV and wind power for each region can be obtained directly from IEA scenarios $^{8}$. The regional stocks of mobile phone and passenger car can be calculated from regional stock level per capita (SPC) and future population development (Population), as shown in 
the following equations:

$$
\begin{aligned}
& S C_{i}^{t}=\frac{K_{i}}{1+e^{a+b t}} \\
& S_{i}^{t}=S P C_{i}^{t} * \text { Population }_{i}^{t}
\end{aligned}
$$

$S P C_{i}^{t}$ is the stock of mobile phones or passenger car per capita in region $i$ at time t, which was assumed to follow the logistic curve towards regional saturation point $K_{i} . S_{i}^{t}$ is the stock of mobile phone or passenger car in region $i$ at time t. Population ${ }_{i}^{t}$ is the population in region $i$ at time t.

Secondly, the outflows $F_{i}^{t}$ (out) of the end of life technologies or products are calculated, as given in Eq. 2.3. The outflows of end-of-life mobile phones, passenger cars, solar PV, and wind power are derived from previous sales or installed capacity. Gallium old scrap generated at the end-of-life applications is derived from the gallium demand into final use products and the lifetime distribution of gallium applications. The Weibull distribution is used to model the product lifespan in this research, and the scale parameter $\alpha$ and the shape parameter $\beta$ which determine the lifetime distribution curve are assumed based on relevant literature as shown in Table S3. The lifespan distribution of gallium applications is shown in Figure S5.

$$
F_{i}^{t}(\text { out })=\sum_{j=0}^{t-1} F_{i}^{j}(\text { in }) * f_{t-j}
$$

Where $\mathrm{j}$ is the lifetime of technologies or products, $f_{t-j}$ is the probability of technology or product $i$ reaching its end of life in the year $t$ based on the Weibull probability distribution function.

Finally, the inflows $F_{i}^{t}($ in $)$ of technologies or products in the given year can be estimated by the flowing equation:

$$
F_{i}^{t}(\text { in })=S_{i}^{t}-S_{i}^{t-1}+F_{i}^{t}(\text { out })
$$

Where $F_{i}^{t}(i n)$ is the sales of mobile phone and passenger car, or the annual installed capacity of solar PV and wind power in region $i$ at time $t$ (inflow), $S_{i}^{t}$ is the stock of mobile phone, passenger car, solar PV and wind power in region $i$ at time $t$, and $F_{i}^{t}($ out $)$ is annual discard flow of mobile phone, passenger car, solar PV and wind power in region $i$ at time $t$ (outflow).

Table S2. Description of input parameters for the SD model

\begin{tabular}{|l|l|l|l|l|}
\hline System & Parameters & Unit & Value & Source \\
\hline \multirow{5}{*}{ Aluminum } & Aluminum production efficiency & $\%$ & 50 & 10 \\
\cline { 2 - 6 } & Alumina production efficiency & $\%$ & 40 & 11 \\
\cline { 2 - 6 } & Production rate of new aluminum scrap & $\%$ & 7 & 12 \\
\cline { 2 - 5 } & Recovery coefficient of old aluminum scrap & $\%$ & 70 & 12 \\
\hline
\end{tabular}




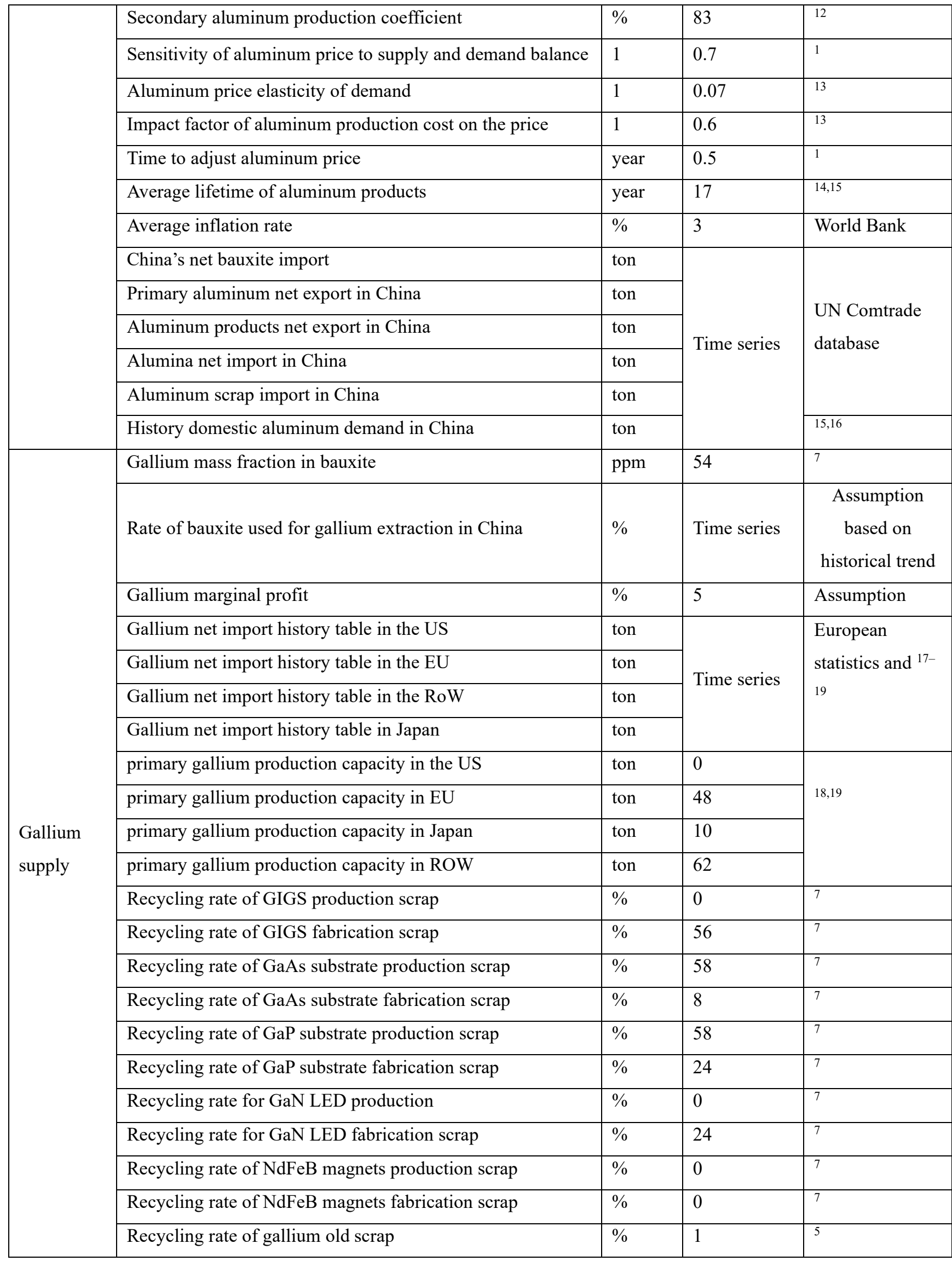




\begin{tabular}{|c|c|c|c|c|}
\hline \multirow{4}{*}{$\begin{array}{l}\text { Gallium } \\
\text { price }\end{array}$} & Price elasticity of gallium demand & 1 & 0.2 & by calculation \\
\hline & Sensitivity of Ga prices to supply and demand balances & 1 & 0.6 & by calculation \\
\hline & Time to adjust gallium price & year & 0.5 & 1 \\
\hline & Impact factor of gallium production cost on price & 1 & 0.6 & 20 \\
\hline \multirow{16}{*}{$\begin{array}{l}\text { Gallium } \\
\text { demand for } \\
\text { LED }\end{array}$} & Population relative growth in each region & $\%$ & Time series & 6 \\
\hline & GaAs/GaP-based LED market share & $\%$ & 30 & 7 \\
\hline & GaN-based LED market share & $\%$ & 70 & 7 \\
\hline & Share of GaAs/GaP LED fabricated on GaAs & $\%$ & 88 & 7 \\
\hline & Thickness of LED chips & $\mathrm{m}$ & $1.4 * 10^{\wedge}(-4)$ & 7 \\
\hline & Thickness of deposition layer of LED & $\mathrm{m}$ & $4 * 10^{\wedge}(-6)$ & 7 \\
\hline & Thickness of GaP substrate & $\mathrm{m}$ & $5.62 * 10^{\wedge}(-4)$ & 7 \\
\hline & Thickness of GaAs substrate & $\mathrm{m}$ & $6.53 * 10^{\wedge}(-4)$ & 7 \\
\hline & Fabrication loss rate of LED & $\%$ & 37 & 7 \\
\hline & Production yield of GaP substrate & $\%$ & 35 & 7 \\
\hline & Production yield of GaAs substrate & $\%$ & 35 & 7 \\
\hline & Production yield of GaN LED compound & $\%$ & 11 & 7 \\
\hline & Gallium intensity in $\mathrm{GaP}$ & $\mathrm{g} / \mathrm{cm}^{3}$ & 2.87 & 7 \\
\hline & Gallium intensity in GaAs & $\mathrm{g} / \mathrm{cm}^{3}$ & 2.56 & 7 \\
\hline & Gallium intensity in GaN & $\mathrm{g} / \mathrm{cm}^{3}$ & 5.12 & 7 \\
\hline & Gallium intensity in AlInGaP & $\mathrm{g} / \mathrm{cm}^{3}$ & 0.96 & 7 \\
\hline \multirow{3}{*}{$\begin{array}{l}\text { Gallium } \\
\text { demand for } \\
\text { ICs }\end{array}$} & Area of GaAs chips per phone & $\mathrm{mm}^{2}$ & Time series & 7 \\
\hline & Thickness of IC chips & $\mathrm{m}$ & $1 * 10^{\wedge}(-4)$ & 7 \\
\hline & Fabrication loss rate of GaAs IC & $\%$ & 22 & 7 \\
\hline \multirow{4}{*}{$\begin{array}{l}\text { Gallium } \\
\text { demand for } \\
\text { CIGS }\end{array}$} & Gallium intensity in CIGS & $\mathrm{kg} / \mathrm{MW}$ & 5 & $7,21-27$ \\
\hline & Deposition yield of CIGS & $\%$ & 45 & 7 \\
\hline & Fabrication loss rate of CIGS & $\%$ & 8 & 7 \\
\hline & Production yield of CIGS & $\%$ & 100 & 7 \\
\hline \multirow{7}{*}{$\begin{array}{l}\text { Gallium } \\
\text { demand for } \\
\text { NdFeB } \\
\text { magnets }\end{array}$} & Share of NdFeB magnets using gallium & $\%$ & 20 & 7 \\
\hline & Gallium intensity in BEV & g/unit & 1.68 & $25,28,29$ \\
\hline & Gallium intensity in PHEV & g/unit & 1.05 & $25,28,29$ \\
\hline & Gallium intensity in wind turbine & $\mathrm{kg} / \mathrm{MW}$ & 2.8 & $7,9,23$ \\
\hline & Gallium intensity in $\mathrm{NdFeB}$ magnets & $\%$ & 0.5 & 7 \\
\hline & Fabrication yield of NdFeB magnets & $\%$ & 70 & 7 \\
\hline & Production yield of NdFeB magnets & $\%$ & 100 & 7 \\
\hline
\end{tabular}


Table S3. Average lifetimes of different gallium applications

\begin{tabular}{lcccc}
\hline Applications & $\begin{array}{c}\text { Distribution } \\
\text { function }\end{array}$ & $\begin{array}{c}\text { Scale } \\
\text { parameter } \alpha\end{array}$ & $\begin{array}{c}\text { Shape } \\
\text { parameter } \beta\end{array}$ & Reference \\
\hline Solar PV & & 25 & 5 & 7,21 \\
Wind power & & 20 & 4 & 7,21 \\
Passenger car & Weibull & 16 & 4.8 & 21,30 \\
Mobile phone & distribution & 3.28 & 2.32 & 7,31 \\
LED & & 10 & 2 & 7,9 \\
Other IT/telecom. & & 6 & 2 & 7,9 \\
\hline
\end{tabular}

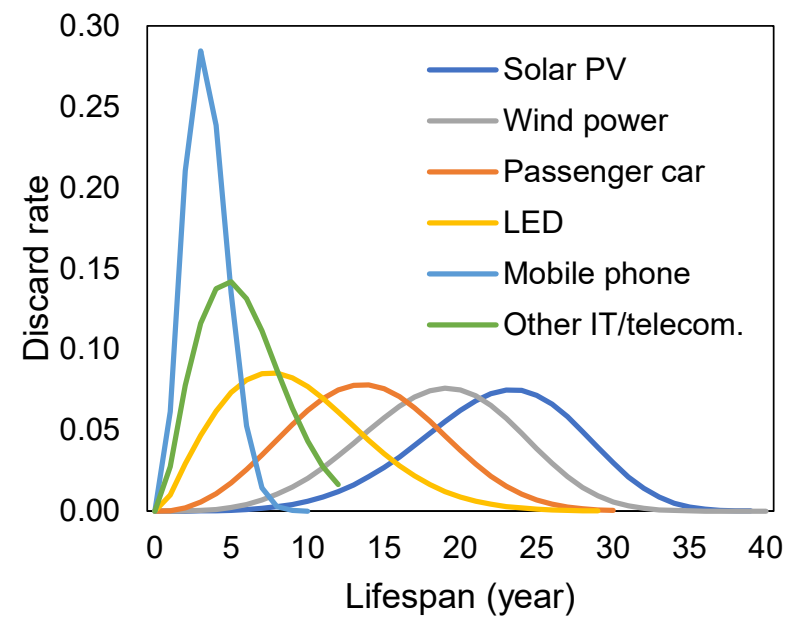

Figure S5. Lifespan distribution of gallium applications

\section{Scenario settings}

For an in-depth analysis of the regional balance of gallium supply and demand, we developed 33 dynamic scenarios combining 9 demand-related variations with 7 supply conditions, as shown in Figure S6.

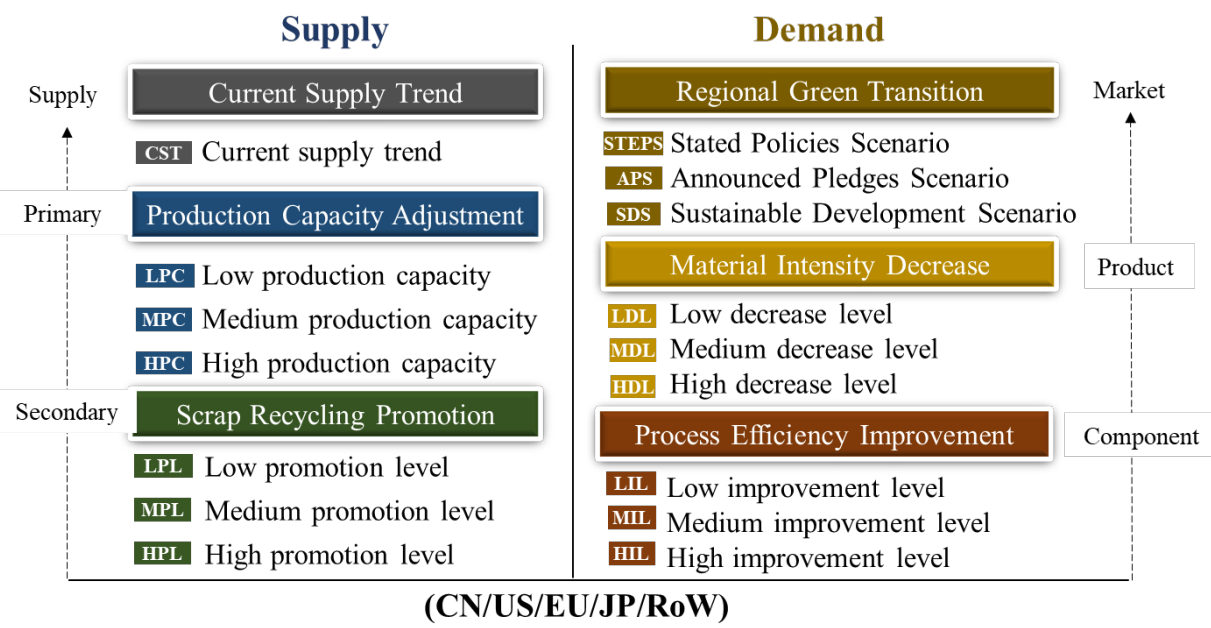

Figure S6. Scenario settings of the gallium supply and demand 


\subsection{Gallium supply scenarios}

\subsubsection{Current supply trend}

In the current supply trend scenario, the gallium supply in each region has been assumed to follow the same trend as its historical development. The gallium production in China is highly dependent on aluminum production, which is determined by bauxite production. In the future, China's bauxite production growth rate is assumed to maintain at the average growth level of 3\% from 2015 to 2019. As the bauxite deposits in the US are not generally suitable for alumina production due to their high silica content ${ }^{18}$, there is currently no gallium production capacity in this region. The EU had suspended primary gallium production in $2016^{19}$. Hence, the future primary gallium production has been assumed to be zero in the US and EU under the current supply trend. For Japan and the RoW, the current primary gallium production level of 3 and 11 tons/year will be continued in the future, respectively ${ }^{19}$.

\subsubsection{Production capacity adjustment}

In the production capacity adjustment scenarios, the production capacity of primary gallium has been assumed to decline after the primary aluminum production peaks due to the saturated in-use stock in China, and other regions highly dependent on China's market would seek to expand their gallium production to meet growing demand, thereafter. To capture the impact of the aluminum cycle on the primary gallium production in China, three saturation levels of aluminum in-use stock in China have been assumed based on Dai et al. ${ }^{15}$ and Liu et al. ${ }^{11}$ as the followings: 337 tons per capita for the low level, 449 tons per capita for the medium level, and 561 tons per capita for the high level. Moreover, different rates of bauxite used for gallium extraction in China have also been assumed under the production capacity adjustment scenarios, as shown in Table S4.

The primary gallium production in the other four regions is assumed to expand to low (the current production capacity), medium (twice as the current production capacity), and high levels (trice as the current production capacity) in 2050. According to USGS ${ }^{18,19}$, the current (2019) gallium production capacity is 0 tons/year in the US, 10 tons/year in Japan, 48 tons/year in the EU, and 62 tons/year in RoW. With the increasing gallium supply risk in the US caused by the tight gallium supply market in China, the likelihood to extract gallium from zinc leach residue or coal fly ash will increase in the US, though not high. Therefore, the gallium production capacity in the US is assumed to be the same as in Japan in this scenario. The primary gallium supply in the production capacity scenario is shown in Figure S7. 
Table S4. Parameters and values for different production capacity adjustment scenarios

\begin{tabular}{|c|c|c|c|c|}
\hline \multirow{2}{*}{ Parameters } & \multirow{2}{*}{ 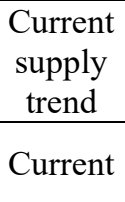 } & \multicolumn{3}{|c|}{ Production capacity adjustment scenarios } \\
\hline & & Low (2050) & $\begin{array}{l}\text { Medium } \\
(2050)\end{array}$ & High (2050) \\
\hline Bauxite production increase rate in China & 0.03 & $\begin{array}{l}\text { Aluminum in- } \\
\text { use stock: } 337 \\
\text { tons per capita }\end{array}$ & $\begin{array}{l}\text { Aluminum in- } \\
\text { use stock: } 449 \\
\text { tons per capita }\end{array}$ & $\begin{array}{l}\text { Aluminum in-use } \\
\text { stock: } 561 \text { tons } \\
\text { per capita }\end{array}$ \\
\hline $\begin{array}{l}\text { Rate of bauxite used for gallium extraction in } \\
\text { China }\end{array}$ & 0.38 & 0.8 & 0.7 & 0.6 \\
\hline Primary gallium production in the US (tons/year) & 0 & 10 & 20 & 30 \\
\hline Primary gallium production in the EU (tons/year) & 0 & 48 & 96 & 144 \\
\hline Primary gallium production in Japan (tons/year) & 3 & 10 & 20 & 30 \\
\hline Primary gallium production in the RoW (tons/year) & 11 & 62 & 124 & 186 \\
\hline
\end{tabular}
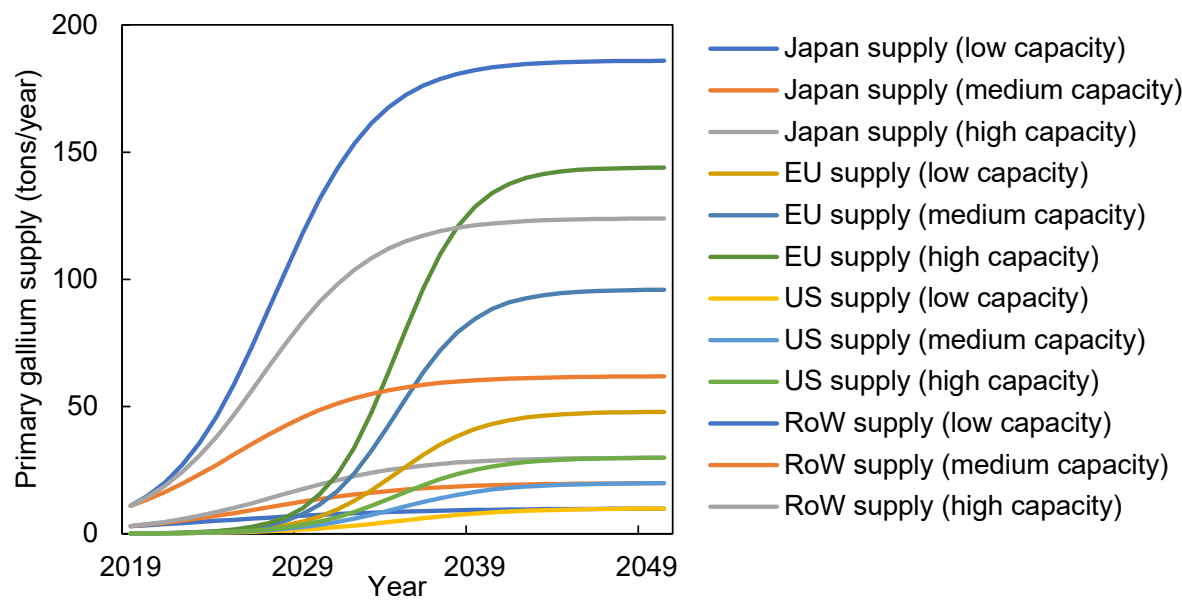

Figure S7. Future primary gallium supply in Japan, EU, US, and the RoW under production capacity adjustment scenarios

\subsubsection{Scrap recycling promotion}

In the scrap recycling promotion scenarios, the impacts of increasing the scrap recycling capacity on the secondary gallium supply will be revealed. The low, medium, and high recycling promotion levels of new gallium scrap and old gallium scrap in 2050 have been set as shown in Table S5, and the increase of recycling rate has been assumed to follow a logistic curve. The recycling levels of new gallium scrap generated in the fabrication or production phase have been kept the same in the studied regions. For old gallium scrap, the recycling rates in the EU and Japan are assumed to be much higher than those in other regions due to their advanced recycling technologies of metal resources. A working recycling system has been installed in Europe for CIGS, including other solar cell types. ${ }^{5}$ 
Table S5. Parameters and values for different promotion scenarios of gallium scrap recycling

\begin{tabular}{|c|c|c|c|c|}
\hline \multirow{2}{*}{ Recycling parameters } & \multirow{2}{*}{$\begin{array}{c}\begin{array}{c}\text { Current supply } \\
\text { trend }\end{array} \\
\text { Current }\end{array}$} & \multicolumn{3}{|c|}{$\begin{array}{l}\text { Scrap recycling } \\
\text { promotion scenario }\end{array}$} \\
\hline & & $\begin{array}{l}\text { Low } \\
(2050)\end{array}$ & $\begin{array}{c}\text { Medium } \\
(2050)\end{array}$ & $\begin{array}{l}\text { High } \\
(2050)\end{array}$ \\
\hline Recycling rate of GIGS production scrap & 0 & 0.3 & 0.6 & 0.9 \\
\hline Recycling rate of GIGS fabrication scrap & 0.56 & 0.64 & 0.72 & 0.9 \\
\hline Recycling rate of GaAs substrate production scrap & 0.58 & 0.67 & 0.8 & 0.9 \\
\hline Recycling rate of GaAs substrate fabrication scrap & 0.08 & 0.34 & 0.54 & 0.8 \\
\hline Recycling rate of GaP substrate production scrap & 0.58 & 0.67 & 0.8 & 0.9 \\
\hline Recycling rate of GaP substrate fabrication scrap & 0.24 & 0.43 & 0.63 & 0.9 \\
\hline Recycling rate for GaN LED production & 0 & 0.3 & 0.6 & 0.9 \\
\hline Recycling rate for GaN LED fabrication scrap & 0.24 & 0.43 & 0.63 & 0.9 \\
\hline Recycling rate of $\mathrm{NdFeB}$ magnets production scrap & 0 & 0.3 & 0.6 & 0.9 \\
\hline \multirow[t]{3}{*}{ Recycling rate of $\mathrm{NdFeB}$ magnets fabrication scrap } & 0 & 0.26 & 0.54 & 0.9 \\
\hline & & China: 0.2 & China: 0.4 & China: 0.6 \\
\hline & & US: 0.3 & US: 0.6 & US: 0.9 \\
\hline \multirow[t]{3}{*}{ Recycling rate of gallium old scrap } & 0.1 & EU: 0.3 & EU: 0.6 & EU: 0.9 \\
\hline & & Japan: 0.3 & Japan: 0.6 & Japan: 0.9 \\
\hline & & ROW: 0.3 & ROW: 0.5 & ROW: 0.8 \\
\hline
\end{tabular}

\subsection{Gallium demand scenarios}

\subsubsection{Regional green transition scenarios}

The implementation of green transition is likely to drive the gallium demand to increase rapidly. Given that, the regional green transition scenarios are set to link the gallium demand to the green transition goals in the studied five regions. In the World Energy Outlook ${ }^{8}$, IEA has developed the Stated Policies Scenario (STEPS), Announced Pledges Scenario (APS), and Sustainable Development Scenario (SDS) by incorporating different global energy transition goals. Accordingly, these three transition scenarios have been considered at the regional level, to reflect the dynamics of regional gallium demand driven by different transition goals. Basically, the scenarios of STEPS, APS and SDS indicate the low, medium, and high levels of gallium demand, respectively. The parameters for the regional green transition scenarios are shown in Table S6, where the values are set for 2050. 
Table S6. Parameters and values for regional green transition scenarios

\begin{tabular}{|c|c|c|c|c|c|c|c|c|c|}
\hline \multirow[b]{2}{*}{ Region } & \multirow[b]{2}{*}{ Scenarios } & \multicolumn{8}{|c|}{ Parameters and values in 2050} \\
\hline & & $\begin{array}{c}\text { Solar PV } \\
\text { installed } \\
\text { capacity } \\
(\mathrm{GW})\end{array}$ & $\begin{array}{c}\text { CIGS } \\
\text { market } \\
\text { share }(\%)\end{array}$ & $\begin{array}{l}\text { Wind } \\
\text { power } \\
\text { installed } \\
\text { capacity } \\
(\mathrm{GW})\end{array}$ & $\begin{array}{c}\text { Direct- } \\
\text { drive wind } \\
\text { turbines } \\
\text { market } \\
\text { share }(\%)\end{array}$ & $\begin{array}{c}\mathrm{EV} \\
\text { market } \\
\text { share } \\
(\%)\end{array}$ & $\begin{array}{l}\text { Share of } \\
\text { NdFeB } \\
\text { magnet } \\
\text { using } \\
\text { gallium } \\
(\%)\end{array}$ & $\begin{array}{l}\text { Mobile } \\
\text { phone } \\
\text { ownership } \\
\text { (unit/per } \\
\text { capita) }\end{array}$ & $\begin{array}{c}\text { LED } \\
\text { penetration } \\
\text { rate }(\%)\end{array}$ \\
\hline \multirow{3}{*}{ China } & STEPS & 1886 & 5 & 858 & 25 & 60 & 40 & 1.1 & 70 \\
\hline & APS & 3231 & 15 & 1385 & 35 & 100 & 60 & 1.2 & 80 \\
\hline & SDS & 3175 & 25 & 1381 & 50 & 100 & 90 & 1.4 & 90 \\
\hline \multirow{3}{*}{ US } & STEPS & 674 & 5 & 292 & 20 & 30 & 40 & 1.15 & 70 \\
\hline & APS & 1314 & 15 & 684 & 30 & 100 & 60 & 1.35 & 80 \\
\hline & SDS & 1314 & 30 & 684 & 40 & 100 & 90 & 1.55 & 90 \\
\hline \multirow{3}{*}{ EU } & STEPS & 441 & 5 & 354 & 20 & 70 & 40 & 1.2 & 70 \\
\hline & APS & 593 & 15 & 702 & 30 & 100 & 60 & 1.4 & 80 \\
\hline & SDS & 593 & 30 & 702 & 40 & 100 & 90 & 1.6 & 90 \\
\hline \multirow{3}{*}{ Japan } & STEPS & 112 & 5 & 66 & 20 & 30 & 40 & 1.2 & 70 \\
\hline & APS & 144 & 10 & 99 & 25 & 100 & 60 & 1.35 & 80 \\
\hline & SDS & 144 & 20 & 99 & 40 & 100 & 90 & 1.55 & 90 \\
\hline \multirow{3}{*}{ RoW } & STEPS & 3047 & 2 & 1423 & 15 & 20 & 40 & 0.9 & 40 \\
\hline & APS & 3811 & 5 & 1760 & 20 & 40 & 60 & 1.1 & 60 \\
\hline & SDS & 5636 & 10 & 3012 & 30 & 60 & 90 & 1.3 & 80 \\
\hline
\end{tabular}

The development of CIGS and wind turbine markets are dependent on the installed capacities of solar PV and wind power, the market share of CIGS and direct drive wind turbines. The regional industrial development goals for solar PV and wind power by 2050 under transition scenarios of STEPS, APS and SDS can be obtained from IEA ${ }^{8}$. Based on historical trends and these obtained data points, the future installed capacity of solar PV and wind power by 2050 could be fitted for each region, as shown in Figure S8. Many researchers have considered different scenarios for the future market share of CIGS and direct drive wind turbines in 2050 , which vary from $0.5 \%$ to $50 \%, 5 \%$ to $50 \%$ respectively, as summarized in Table S7. Based on those studies, we set different market shares for these two technologies in each region in 2050 (in Table S6), and their increases have been assumed to follow a logistic curve, as shown in Figure S9. 

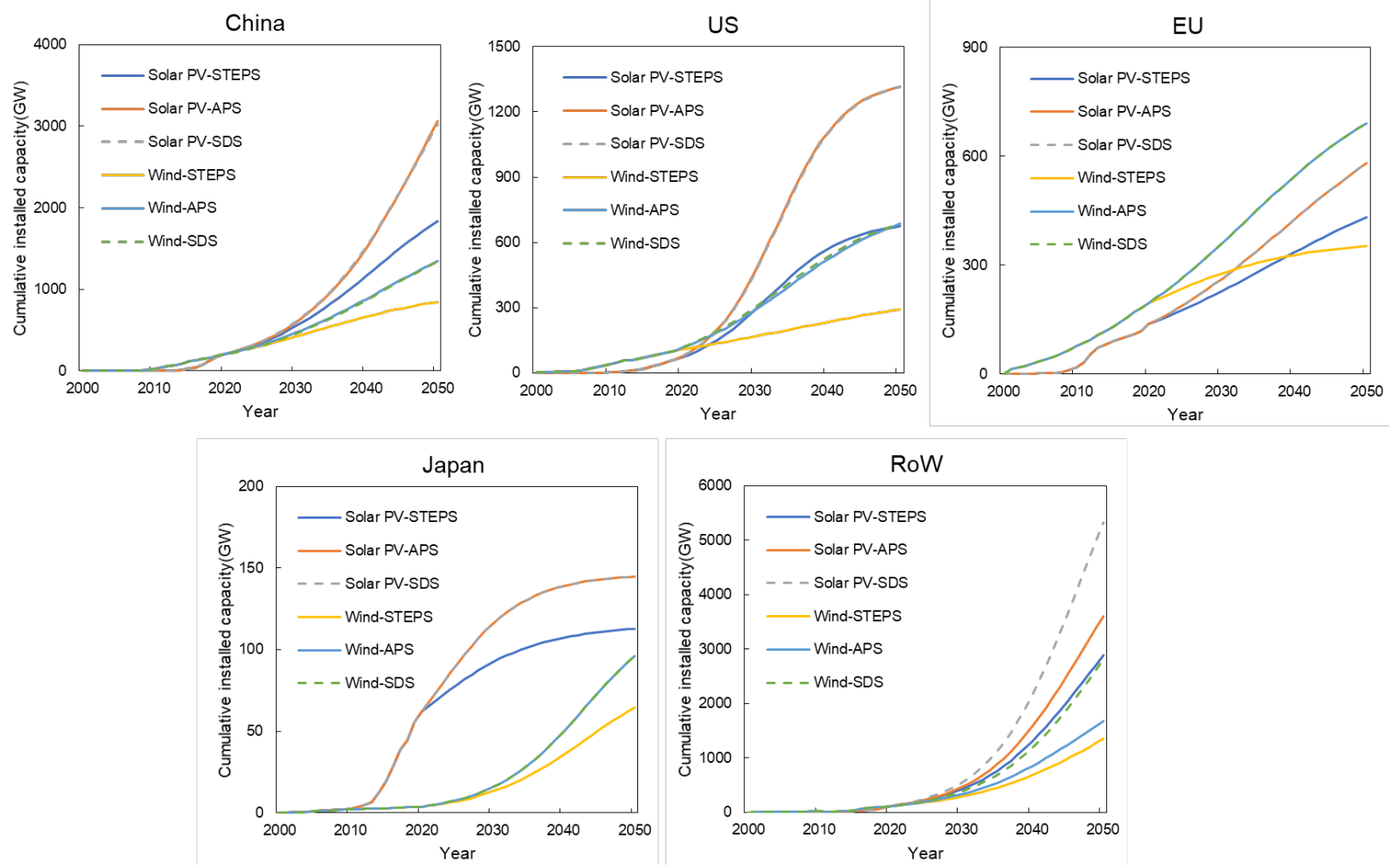

Figure S8. The cumulative installed capacity of solar PV and wind power under different green transition scenarios in the studies five regions

Table S7. Future market share (\%) of CIGS and direct drive wind turbines in existing studies

\begin{tabular}{|c|c|c|c|c|c|c|c|c|c|c|}
\hline \multirow[b]{2}{*}{ Region } & \multicolumn{5}{|c|}{ CIGS } & \multicolumn{5}{|c|}{ Direct drive wind turbines } \\
\hline & Current & $\begin{array}{l}\text { Low } \\
(2050)\end{array}$ & $\begin{array}{l}\text { Base } \\
(2050)\end{array}$ & $\begin{array}{l}\text { High } \\
(2050)\end{array}$ & References & Current & $\begin{array}{c}\text { Low } \\
(2050)\end{array}$ & $\begin{array}{l}\text { Base } \\
(2050)\end{array}$ & $\begin{array}{l}\text { High } \\
(2050)\end{array}$ & References \\
\hline \multirow{4}{*}{ World } & \multirow{4}{*}{1.9} & 5 & & 35 & 32 & & 20 & 30 & 50 & 9,21 \\
\hline & & 5 & 20 & 40 & 7 & 20 & 20 & 25 & 40 & 22 \\
\hline & & 20 & 30 & 50 & 21,33 & & & & 54 & 34 \\
\hline & & 0.5 & 4.5 & 10 & 22 & & & & & \\
\hline \multirow{2}{*}{ China } & & & 16.67 & 26 & 23 & & & & 50 & 23 \\
\hline & 5 & & & 25 & 35 & & & 35 & & 35 \\
\hline US & & 5 & & 50 & 24 & & 5 & & 50 & 24 \\
\hline EU & 1.9 & 0.5 & 4.5 & 10 & 22 & 15 & 15 & 20 & 35 & 22 \\
\hline Germany & 1.9 & 2 & & 30 & 36 & & 15 & & 40 & 36 \\
\hline
\end{tabular}



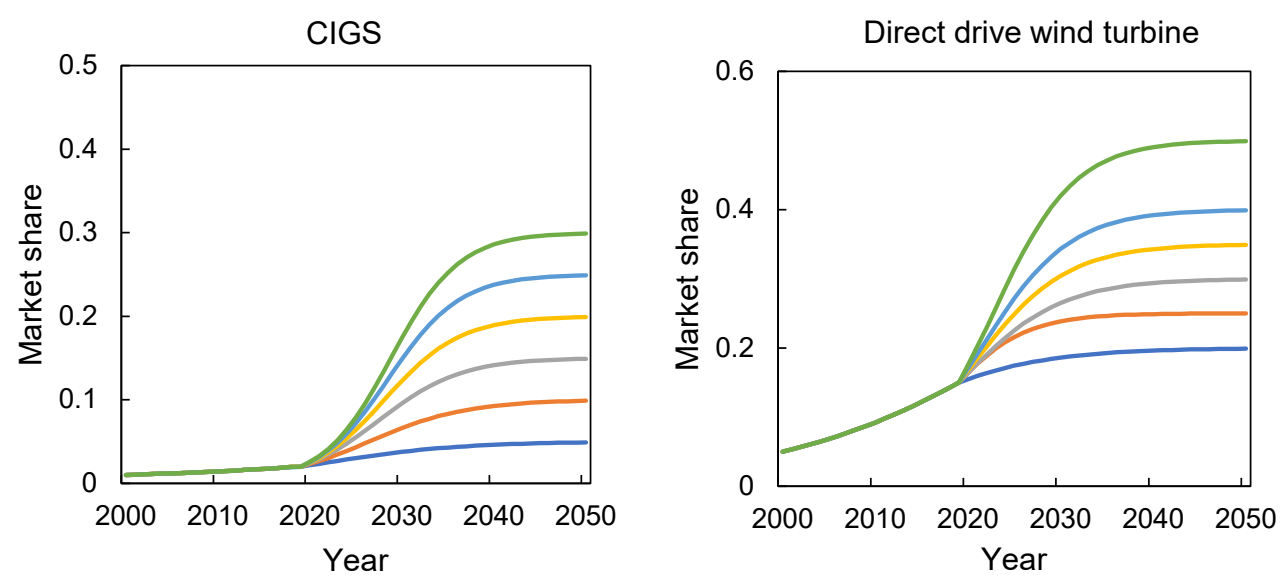

Figure S9. Market share of CIGS and direct wine turbine

The gallium demand for the EVs market is mainly dependent on passenger car sales and the EV market share. Different ownership levels of passenger cars are set for the studied five regions to estimate their passenger car sales. The markets of passenger cars in the US, EU, and Japan are expected to gradually saturate in the coming decades. Thus, we have assumed that the ownerships of passenger cars in these three regions will increase slightly, which reaches 0.85 per capita for the US, 0.6 per capita for the EU, and 0.57 per capita for Japan by 2050. An increasing trend in the penetration market of passenger cars can be anticipated in China due to its rapid expansion in the transportation market. The passenger car ownership in China is assumed to reach the current level of that in Korea and Japan by 2050 , i.e. 0.4 per capita. For the RoW, the passenger car ownership in 2050 is set to be 0.2 per capita, which is the current average levels of that in China ( 0.1 per capita) and Korea ( 0.3 per capita). Based on the future passenger car ownership, a stock-driven model could be used to predict the regional passenger car sales, as described in Section 2 previously.

Various policies have been implemented globally, to promote the deployment of $\mathrm{EVs}^{37}$. We have assumed different EV market shares by 2050 for each region to reflect the dynamic development paces of the regional EV industry under different transition goals, as shown in Table S6 and Figure S10. Based on the New Energy Automobile Industry Plan in China (2021-2035) ${ }^{38}$ and the Carbon Neutrality Ambitions before 2060 in China $^{39}$, the EV shares have been set to be $60 \%, 100 \%, 100 \%$ by 2050 with different growth speed in China under the STEPS, APS and SDS, respectively. With the implementation of the European Union Sustainable and Smart Mobility Strategy ${ }^{40}$, and the European Union net zero 2050 target $^{41}$, a number of European countries have advanced their ban on ICE vehicles and speed up the efforts on the EV deployment. Thus, the EV market share in the EU has been assumed to reach 100\% under the APS and SDS, and 70\% under the STEPS by 2050 .

In anticipation of the announced ICE vehicle ban in the mid-2030s and the 2050 net zero pledge 
in $\mathrm{Japan}^{42}$, the EV market share in Japan has been assumed to reach $100 \%$ by 2050 under the APS and SDS, and only $30 \%$ by 2050 under the STEPS driven by the country's current fuel economy standards ${ }^{37}$. Similarly, with the United States announcing plans to subsidize EVs and charging infrastructure, and reach net-zero emissions by $2050^{37}$, a share of $100 \%$ has been set for the EV market in the US under the APS and SDS. Many countries in the RoW region have not yet developed a clear vision or set targets for electric mobility, thus the EV market share in the RoW will be lagging behind the other four regions, which has been assumed to be $20 \%, 40 \%, 60 \%$ by 2050 under the STEPS, APS and SDS, respectively.
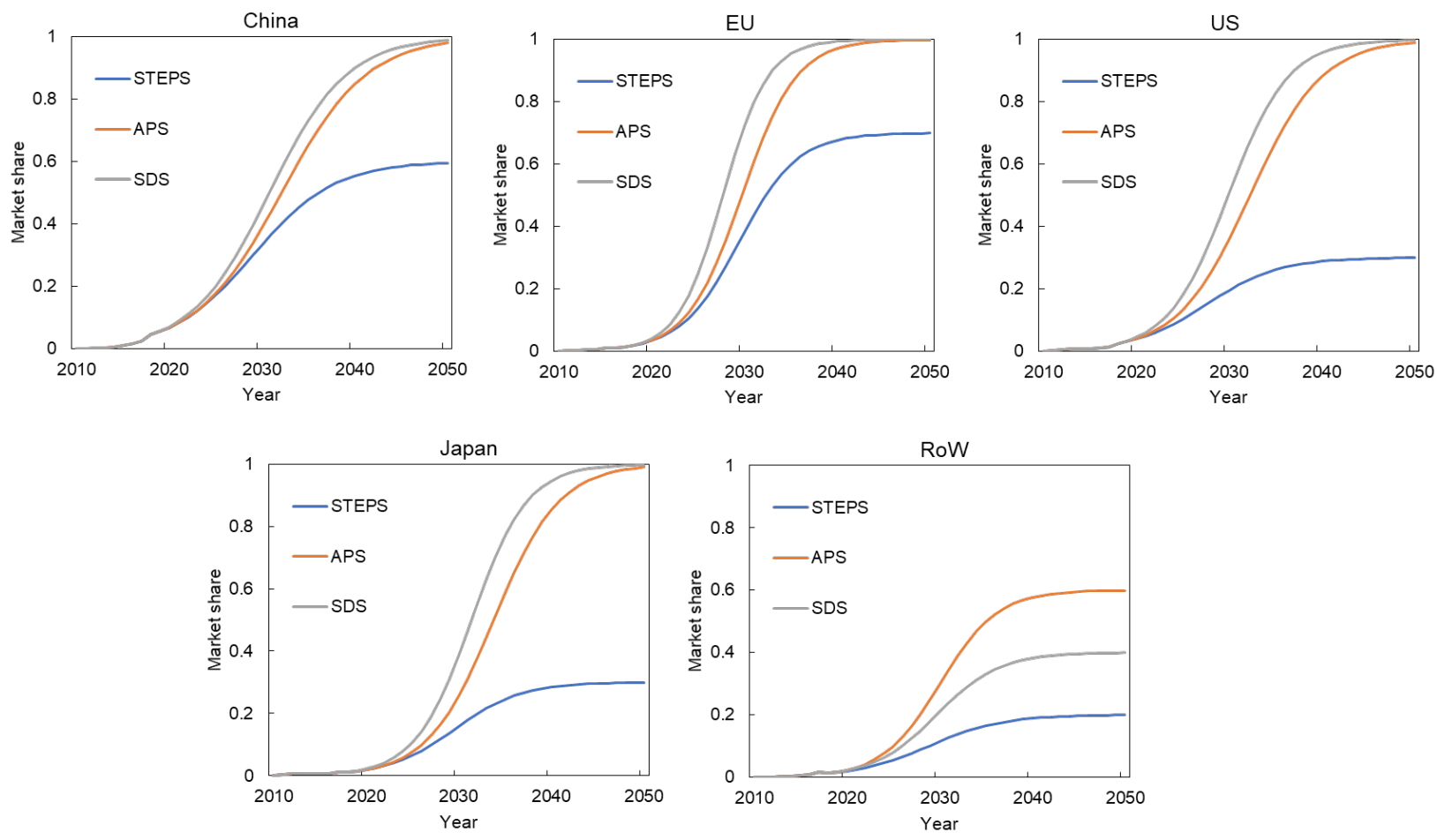

Figure S10. EV market share under different scenarios in the studied five regions

The share of gallium-containing $\mathrm{NdFeB}$ magnets and the population growth determine the gallium demand for $\mathrm{NdFeB}$ magnets used in other applications. Starting from a $20 \%$ market share for gallium-containing $\mathrm{NdFeB}$ magnets, ${ }^{7}$ three scenarios, i.e. the low, medium, and high market penetration rates, have been created for the future, assuming that it gradually increases up to $40 \%$, $60 \%$, and 90\%, respectively, as shown in Figure S11. The United Nations (UN) has projected the average annual rate of future population change by regions, ${ }^{6}$ including the median, lower 80 , and upper 80 values, which are selected to represent the medium, low, and high scenario for the population growth rate in the studies five regions. 


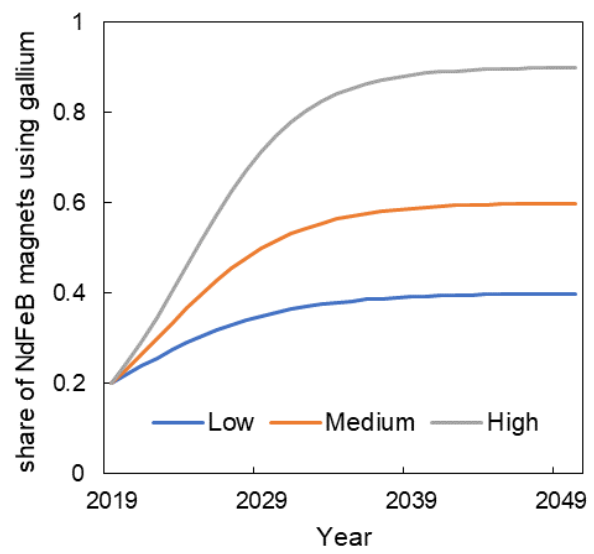

Figure S11. The share of $\mathrm{NdFeB}$ magnet using gallium under different scenarios

To reflect the varying gallium demand for ICs, three scenarios including the low, medium, and high levels for mobile phone ownership are set for the studied five regions. Based on the mobile phone subscription data and population data from the UN, the historical ownership of mobile phone in use per capita in each region are calculated. To make a future projection, a logistic curve is fitted to the calculated number of mobile phones in use per capita. The global saturation value of mobile phone ownership is 1.1 per capita. $^{7}$ Taking the global average level and regional historical trend into consideration, the low, medium, and high ownership scenarios of mobile phones in use per capita for each region are created, as shown in Figure S12. The low scenario assumes that the current ownership remains the same in the future; the medium scenario assumes that it will increase following the historical trend; the high scenario assumes an ambitious saturation level of the regional ownership of mobile phones per capita.

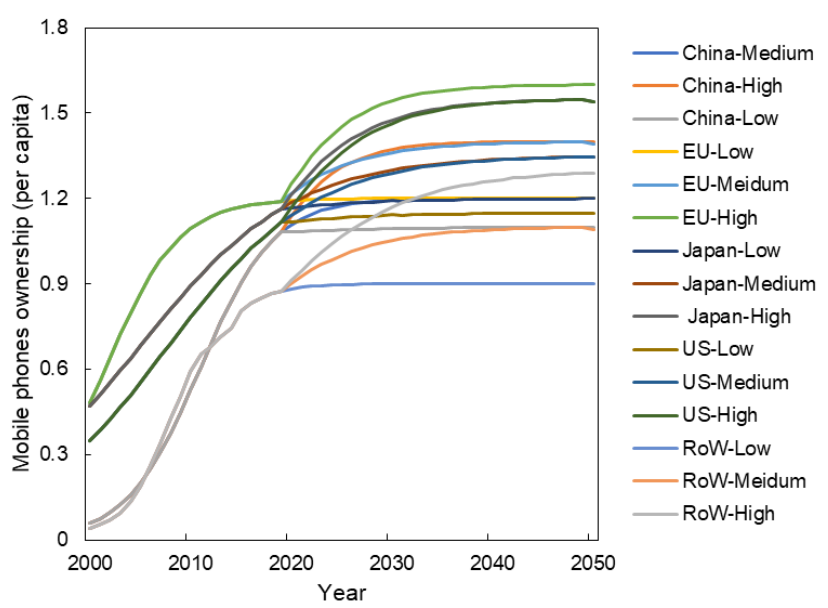

Figure S12. Mobile phones ownership under different scenarios in the studied five regions

The gallium demand for LEDs is highly driven by the regional LED market development. 70\% of the lighting market in China, the EU, the US, and Japan is currently dominated by LED, whereas it is only $20 \%$ in the $\mathrm{RoW},{ }^{43}$ which means that there is a promising potential to expand the LED 
market in this region. Three scenarios have been created for the future market penetration rate of LEDs in each region. The low scenario assumes that it will remain at $70 \%$ in China, the EU, the US and Japan, while it will reach $40 \%$ by 2050 in the RoW. The medium scenario assumes that the market penetration rate of LEDs will slightly increase to $80 \%$ in China, the EU, the US and Japan, and an increase to $60 \%$ in the RoW will be anticipated in 2050 . The high scenario assumes that it will reach a high level of $90 \%$ in China, the EU, the US, and Japan, while it will increase to $80 \%$ in the RoW in 2050. Moreover, different population increase scenarios have been also considered in the gallium demand for LEDs. The change of the future market penetration rate of LEDs is shown in Figure S13.

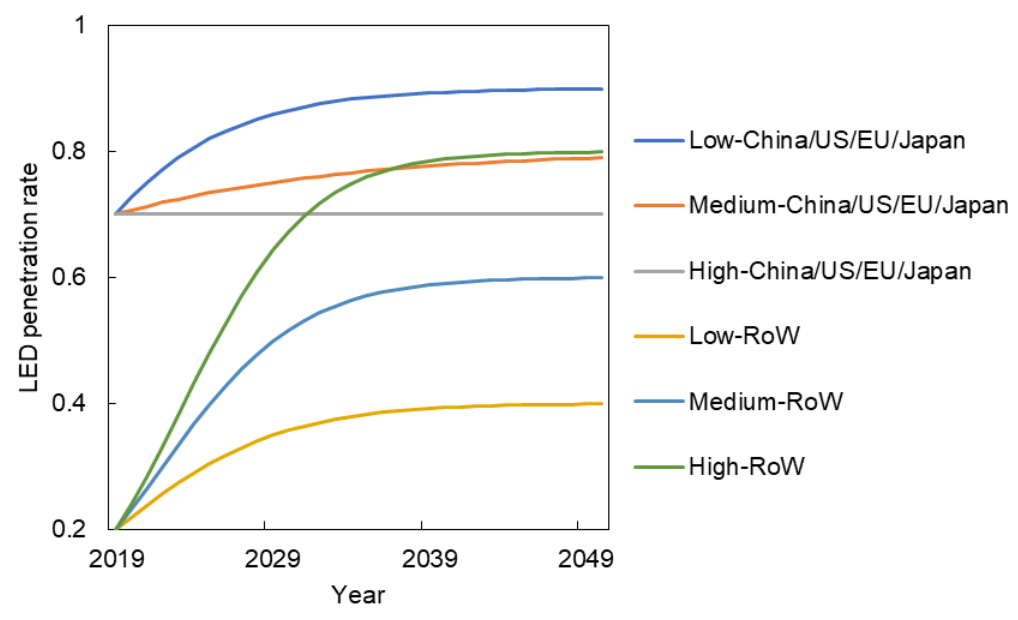

Figure S13. Future LED penetration rate under different scenarios in the studied five regions

\subsubsection{Material intensity reduction scenarios}

The final gallium products provide services to meet the market demand and technological development. Gallium demand into the final use phase is highly dependent on the gallium intensity in final products. In the green transition scenario, the gallium intensity in all applications has been assumed to remain at the current level in the future. To reflect the potential impacts of material intensity reduction on the gallium demand, three reduction scenarios including low, medium, and high levels, have been set, as shown the Table S8. The gallium intensity in CIGS, wind turbines, electric cars, and $\mathrm{NdFeB}$ magnets in other applications has been assumed to be $10 \%, 30 \%, 50 \%$ lower than the current level in the low, medium, and high reduction scenarios in 2050, respectively. The gallium intensity in LEDs and ICs is determined by the gallium intensity in $\mathrm{GaAs} / \mathrm{GaP} / \mathrm{GaN}$ substrates and their thickness, which have been assumed to decrease by $10 \%, 20 \%, 30 \%$, respectively compared to the current level in the low, medium, and high reduction scenarios. The decrease in those parameters in the future has been assumed to follow a logistic curve. 
Table S8. Parameters and values for different reduction scenarios of gallium intensity

\begin{tabular}{cccccc}
\hline Parameters & Unit & Current & $\begin{array}{c}\text { Low } \\
(2050)\end{array}$ & $\begin{array}{c}\text { Medium } \\
(2050)\end{array}$ & $\begin{array}{c}\text { High } \\
(2050)\end{array}$ \\
\hline Gallium intensity in wind turbines & $\mathrm{kg} / \mathrm{MW}$ & 2.8 & 2.52 & 1.96 & 1.4 \\
Gallium intensity in CIGS & $\mathrm{kg} / \mathrm{MW}$ & 5 & 4.5 & 3.5 & 2.5 \\
Gallium intensity in BEV & $\mathrm{g} / \mathrm{unit}$ & 1.68 & 1.5 & 1.18 & 0.84 \\
Gallium intensity in PHEV & $\mathrm{g} / \mathrm{unit}$ & 1.05 & 0.9 & 0.7 & 0.5 \\
Gallium intensity in GaAs & ton $/ \mathrm{m}^{3}$ & 2.56 & 2.3 & 2.05 & 1.79 \\
Gallium intensity in GaP & ton $/ \mathrm{m}^{3}$ & 2.87 & 2.58 & 2.3 & 2 \\
Gallium intensity in GaN & ton/m $\mathrm{m}^{3}$ & 5.12 & 4.6 & 4.1 & 3.58 \\
Thickness of GaAs substrate & $\mathrm{m}$ & $6.53 * 10^{(-4)}$ & $5.88^{*} 10^{(-4)}$ & $5.2^{*} 10^{(-4)}$ & $4.57^{*} 10^{(-4)}$ \\
Thickness of GaP substrate & $\mathrm{m}$ & $5.62^{*} 10^{(-4)}$ & $5.06^{*} 10^{(-4)}$ & $4.5^{*} 10^{(-4)}$ & $3.93^{*} 10^{(-4)}$ \\
Thickness of deposition layer of LEDs & $\mathrm{m}$ & $4 * 10^{(-6)}$ & $3.6^{*} 10^{(-6)}$ & $3.2^{*} 10^{(-6)}$ & $2.8^{*} 10^{(-6)}$ \\
Thickness of IC chips & $\mathrm{m}$ & $1 * 10^{(-4)}$ & $0.9^{*} 10^{(-4)}$ & $0.8^{*} 10^{(-4)}$ & $0.7 * 10^{(-4)}$ \\
\hline
\end{tabular}

\subsubsection{Process efficiency improvement scenarios}

The process efficiency in the production and fabrication phases also influences the gallium demand. Referring to the existing studies ${ }^{5,7}$, the high, medium, and low improvement scenarios of process efficiency have been created to explore the potential of gallium process efficiency improvement. The related parameters and values in current and 2050 are shown in Table S9. The improvement of those parameters in the future has been assumed to follow a logistic curve.

Table S9. Parameters and values for different improvement scenarios of process efficiency

\begin{tabular}{cccccc}
\hline Parameters & Unit & Current & $\begin{array}{c}\text { Low } \\
(2050)\end{array}$ & $\begin{array}{c}\text { Medium } \\
(2050)\end{array}$ & $\begin{array}{c}\text { High } \\
(2050)\end{array}$ \\
\hline Fabrication loss rate of GaAs IC & $\%$ & 22 & 18 & 14 & 10 \\
Production yield of GaAs substrate & $\%$ & 35 & 50 & 65 & 80 \\
Fabrication loss rate of LEDs & $\%$ & 37 & 31 & 26 & 22 \\
Deposition yield of LEDs & $\%$ & 11 & 14 & 0.17 & 20 \\
Production yield of GaN LED & $\%$ & 11 & 14 & 0.17 & 20 \\
Production yield of GaP substrate & $\%$ & 35 & 40 & 45 & 50 \\
Production yield of CIGS & $\%$ & 100 & 100 & 100 & 100 \\
CIGS fabrication loss rate & $\%$ & 8 & 6 & 4 & 2 \\
Deposition yield CIGS & $\%$ & 45 & 60 & 70 & 80 \\
Fabrication yield in NdFeB magnets & $\%$ & 70 & 75 & 80 & 85 \\
Production yield in NdFeB magnets & $\%$ & 100 & 100 & 100 & 100 \\
\hline
\end{tabular}




\section{Model testing and validation}

After accomplishing the model, we conducted an extreme condition test and behavior sensitivity analysis to test the structure validity and behavior of the developed model. The uncertainty analysis has also been performed based on the Monte Carlo simulations.

\subsection{Extreme condition test}

The extreme condition test is used to verify whether the model can reflect the system change when an extreme situation occurs. The varying gallium supply/demand ratio could reflect the balance conditions of gallium supply and demand, dynamically. As the change of gallium supply is driven by the gallium demand market in our model, we set the variable gallium demand as an impact factor for the extreme condition test. When the gallium demand increases dramatically, the gallium supply should also grow as feedback to keep a balanced gallium market, unless the gallium supply exceeds its supply potential.

We selected the global gallium supply/demand ratio under the supply scenario of CST and the demand scenario of APS as a base condition to test the impacts of the extreme condition on the gallium market. Considering the gallium's important role in enabling the worldwide adoption of solar PV and wind power, we selected the market share and installed capacity of CIGS and direct drive wind turbines as the control parameters to drive the gallium demand. To reflect the extreme high condition of gallium demand, the market shares of CIGS and wind turbines are set to grow to $90 \%$, and the annual installed capacity of solar PV is set to be $25 \%$ higher than that in the base conditions.

Figure S14 shows that, compared to the base condition, the gallium demand increases greatly under the extreme condition, which in turn drives the gallium supply to grow to meet the soaring demand. However, the gallium supply/demand ratio under the extremely high demand condition gradually decreases after 2035. This is because the growth of gallium supply is limited by its maximum supply potential. This indicates the well-working feedback mechanism between the gallium demand and gallium supply, as well as the effective internal structure of the model. 


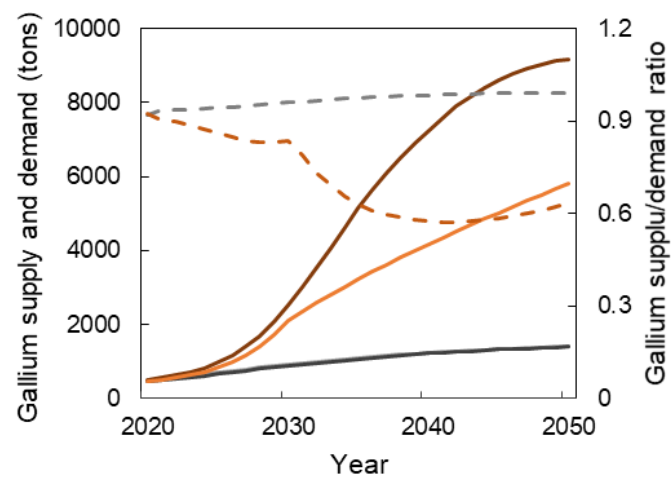

Gallium demand (base condition)

_ Gallium supply (base condition)

Gallium demand (extreme demand condition)

Gallium supply (extreme demand condition)

- - - Gallium supply/demand ratio (base condition)

- - - Gallium supply/demand ratio (extreme demand condition)

Figure S14. The changes of global gallium supply and demand under extreme demand condition

\subsection{Behavior sensitivity test}

Sensitivity analysis conducted by using the Monte Carlo simulation technique was conducted to test the robustness of the simulated results. We take the supply scenario of low production capacity and the demand scenario of APS as a proxy to assess the impacts of the parameters, shown in Table $\mathrm{S} 10$, on the global and regional gallium supply and demand. $\pm 10 \%$ of variations based on the original values are applied to those parameters. Results of the sensitivity analysis for the global gallium supply and demand are shown in Figures S15. The black line means the gallium supply or demand under the original value of the parameters, and the yellow shaded area means the changes of gallium supply or demand caused by the variation of the parameter values.

Table S10. Parameters changes for the sensitivity analysis

\begin{tabular}{|c|c|c|c|c|}
\hline & Parameters & $\begin{array}{c}\text { Original } \\
\text { value }\end{array}$ & $\begin{array}{c}\text { Low value } \\
\qquad(-10 \%)\end{array}$ & $\begin{array}{c}\text { High value } \\
(+10 \%)\end{array}$ \\
\hline \multirow{12}{*}{$\begin{array}{l}\text { Gallium } \\
\text { supply }\end{array}$} & Gallium mass fraction in bauxite (ppm) & 54 & 48.6 & 59.4 \\
\hline & Marginal profit of gallium production ( $\%)$ & 5 & 4.5 & 5.5 \\
\hline & Recycling rate of GIGS production scrap & 0 & 0 & 0.10 \\
\hline & Recycling rate of GIGS fabrication scrap & 0.56 & 0.50 & 0.62 \\
\hline & Recycling rate of GaAs substrate production scrap & 0.58 & 0.52 & 0.64 \\
\hline & Recycling rate of GaAs substrate fabrication scrap & 0.08 & 0.07 & 0.09 \\
\hline & Recycling rate of GaP substrate production scrap & 0.58 & 0.52 & 0.64 \\
\hline & Recycling rate of $\mathrm{GaP}$ substrate fabrication scrap & 0.24 & 0.22 & 0.26 \\
\hline & Recycling rate for GaN LED production scrap & 0 & 0 & 0.10 \\
\hline & Recycling rate for GaN LED fabrication scrap & 0.24 & 0.22 & 0.26 \\
\hline & Recycling rate of $\mathrm{NdFeB}$ magnets production scrap & 0 & 0 & 0.10 \\
\hline & Recycling rate of $\mathrm{NdFeB}$ magnets fabrication scrap & 0 & 0 & 0.10 \\
\hline Gallium & Fabrication loss rate of LED & 0.37 & 0.33 & 0.40 \\
\hline
\end{tabular}




\begin{tabular}{|c|c|c|c|c|}
\hline \multirow{2}{*}{ demand } & \multirow{2}{*}{$\begin{array}{l}\text { Fabrication loss rate of GaAs IC } \\
\text { Fabrication loss rate of CIGS }\end{array}$} & \multirow{2}{*}{$\begin{array}{l}0.22 \\
0.08\end{array}$} & \multirow{2}{*}{$\begin{array}{l}0.20 \\
0.07\end{array}$} & \multirow{2}{*}{$\begin{array}{l}0.24 \\
0.09\end{array}$} \\
\hline & & & & \\
\hline & Fabrication yield of $\mathrm{NdFeB}$ magnets & 0.70 & 0.63 & 0.77 \\
\hline & Production yield of GaP substrate & 0.35 & 0.32 & 0.39 \\
\hline & Production yield of GaAs substrate & 0.35 & 0.32 & 0.39 \\
\hline & Production yield of GaN LED compound & 0.11 & 0.10 & 0.12 \\
\hline & Production yield of CIGS & 1.00 & 0.90 & 1.00 \\
\hline & Production yield of $\mathrm{NdFeB}$ magnets & 1.00 & 0.90 & 1.00 \\
\hline & Thickness of deposition layer of LED $(\mu \mathrm{m})$ & 4 & 3.6 & 4.4 \\
\hline & Thickness of GaP substrate $(\mu \mathrm{m})$ & 562 & 506 & 618 \\
\hline & Thickness of GaAs substrate $(\mu \mathrm{m})$ & 653 & 588 & 718 \\
\hline & Thickness of IC chips $(\mu \mathrm{m})$ & 100 & 90 & 110 \\
\hline & Gallium intensity in $\mathrm{GaP}\left(\mathrm{g} / \mathrm{cm}^{3}\right)$ & 2.87 & 2.583 & 3.157 \\
\hline & Gallium intensity in $\mathrm{GaAs}\left(\mathrm{g} / \mathrm{cm}^{3}\right)$ & 2.56 & 2.304 & 2.816 \\
\hline & Gallium intensity in $\mathrm{GaN}\left(\mathrm{g} / \mathrm{cm}^{3}\right)$ & 5.12 & 4.608 & 5.632 \\
\hline & Gallium intensity in CIGS (kg/MW) & 5 & 4.5 & 5.5 \\
\hline & Gallium intensity in BEV (g/unit) & 1.68 & 1.51 & 1.85 \\
\hline & Gallium intensity in PHEV ( $\mathrm{g} / \mathrm{unit}$ ) & 1.05 & 0.95 & 1.16 \\
\hline & Gallium intensity in wind turbine $(\mathrm{kg} / \mathrm{MW})$ & 2.80 & 2.52 & 3.08 \\
\hline & Gallium intensity in $\mathrm{NdFeB}$ magnets (\%) & 0.5 & 0.45 & 0.55 \\
\hline
\end{tabular}
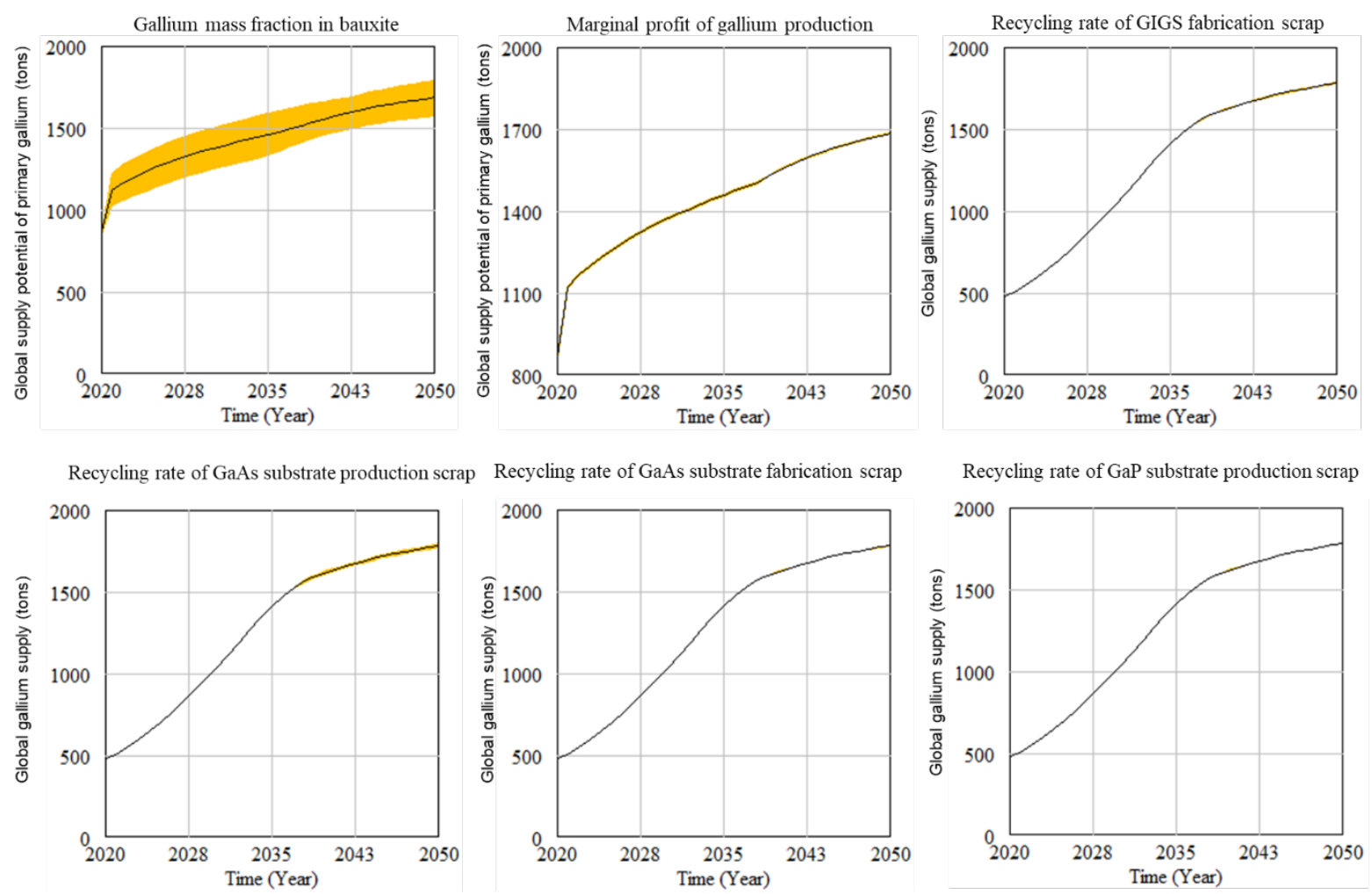

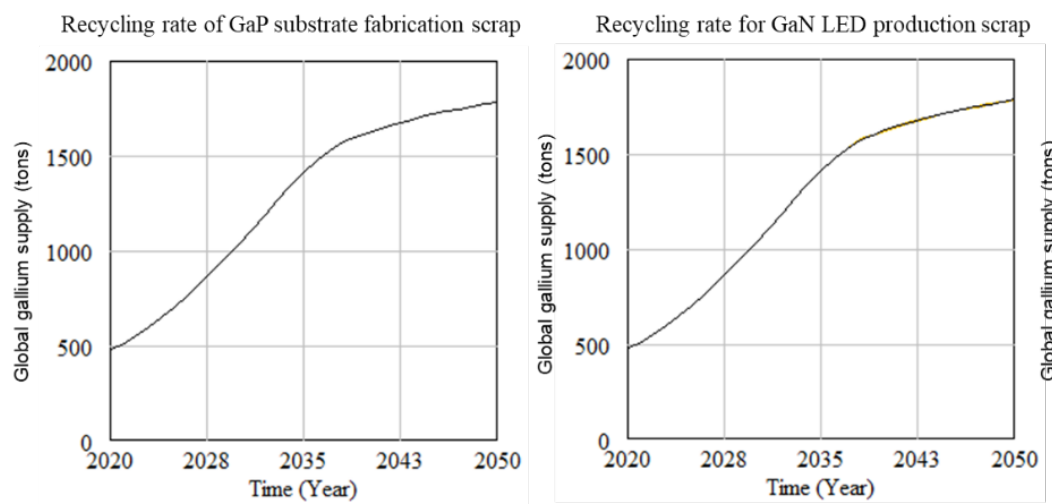

Recycling rate for GaN LED fabrication scrap
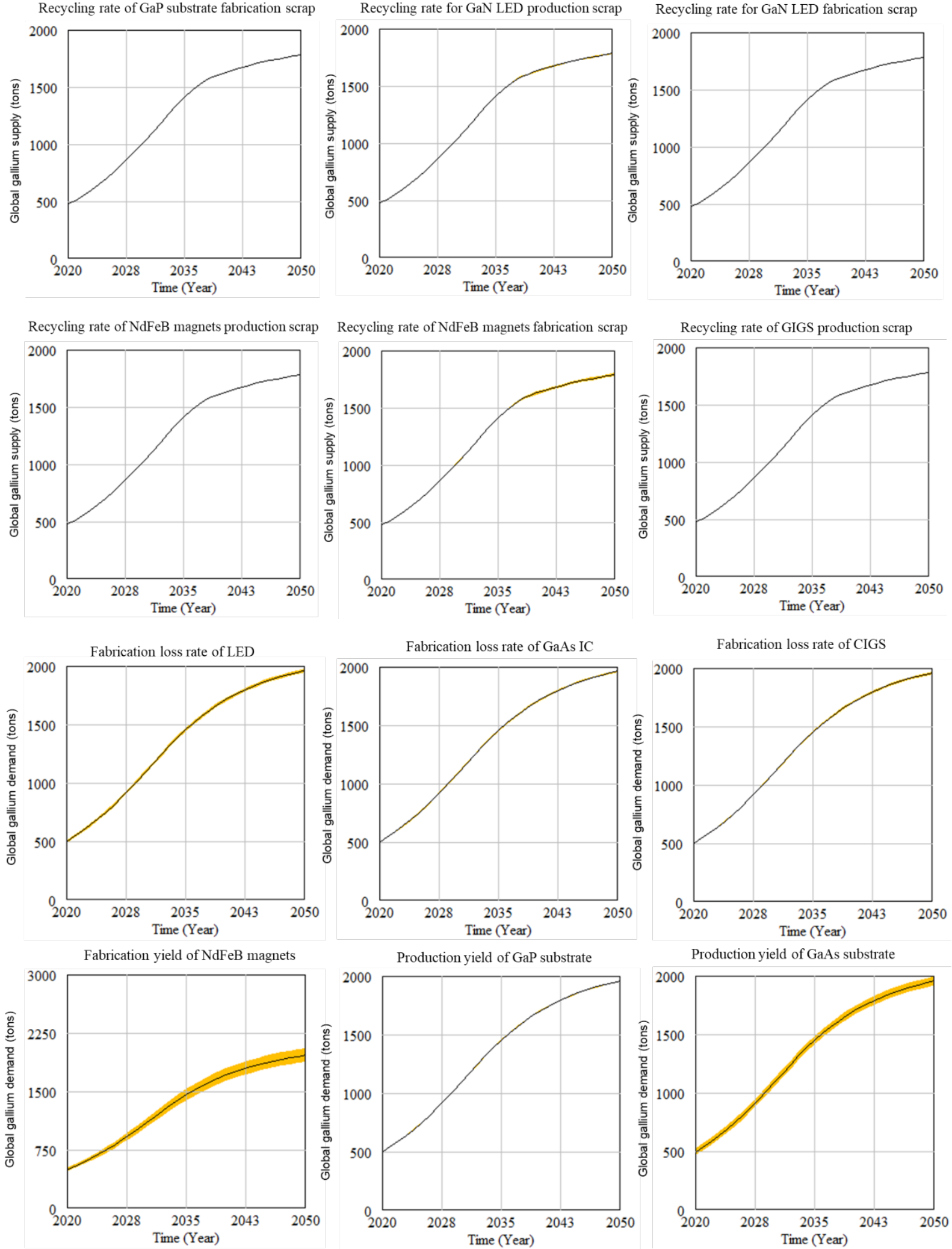

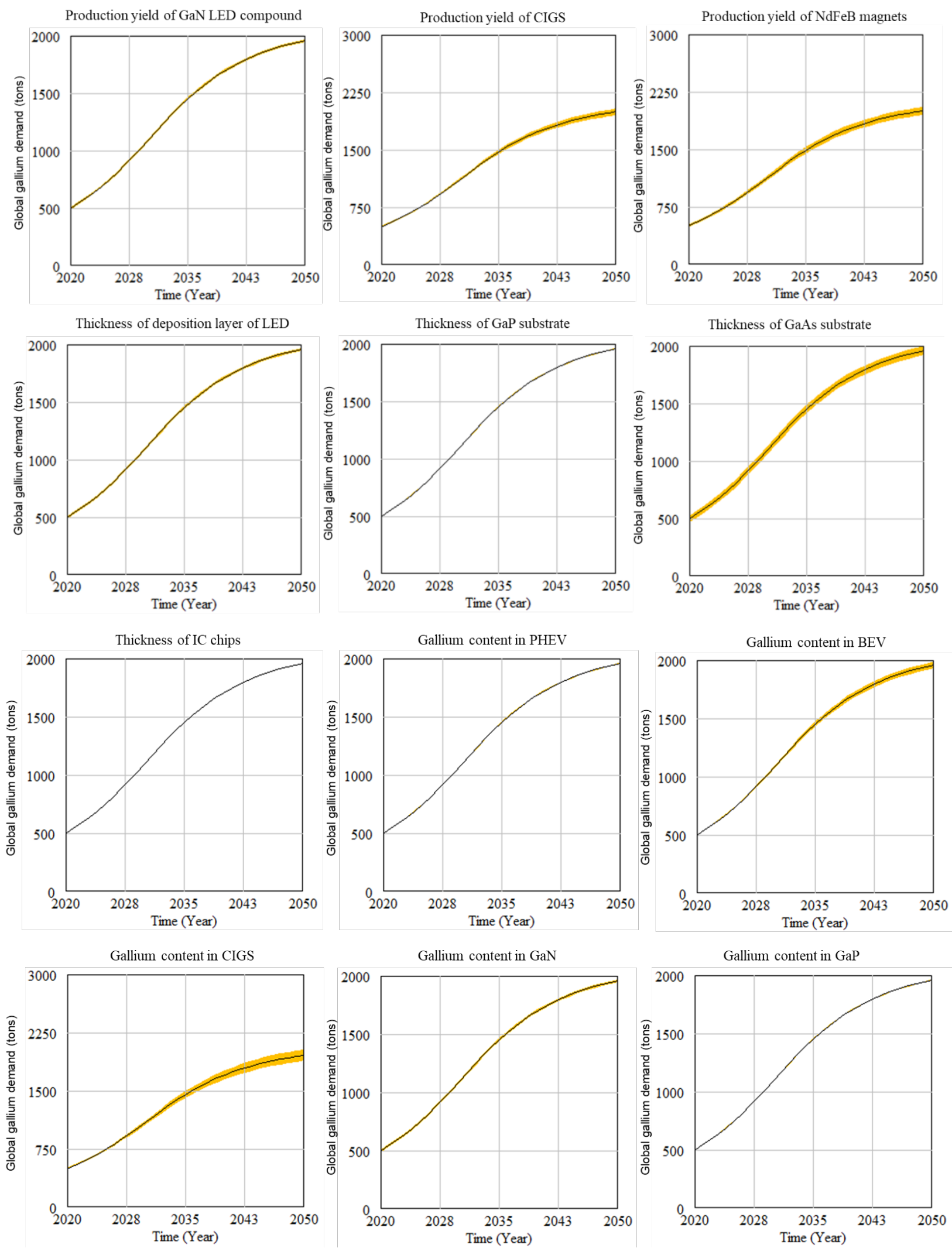

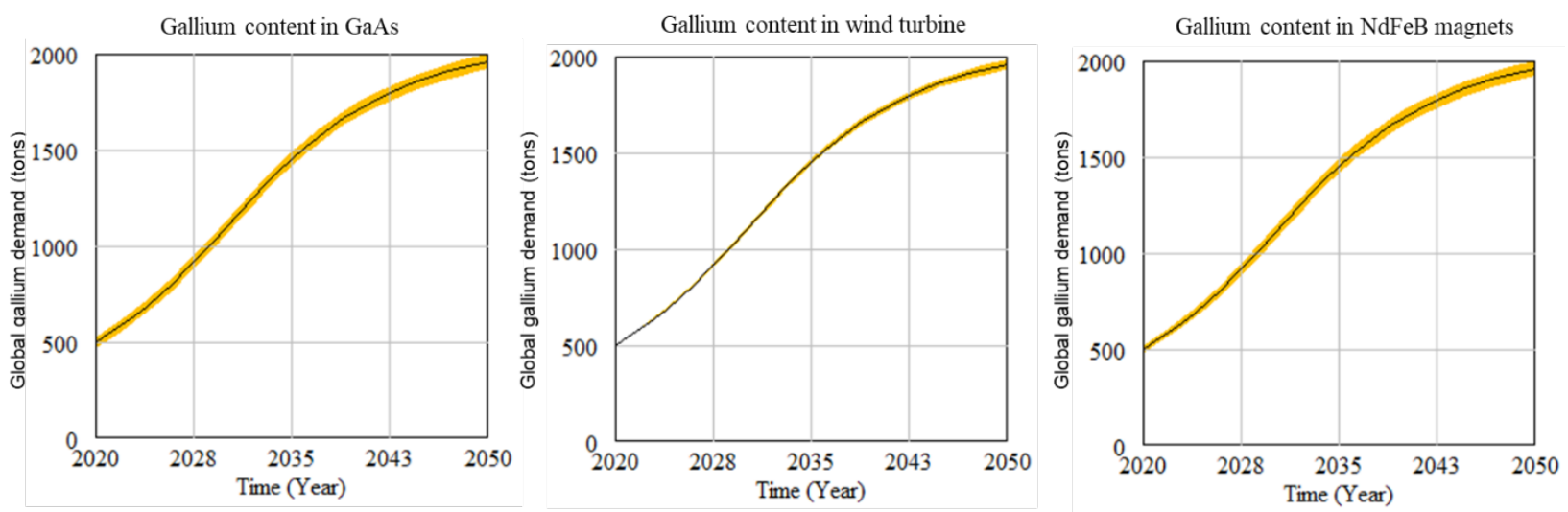

Figure S15. Sensitivity analysis results of gallium supply and demand.

\subsection{Uncertainty analysis}

We conducted a Monte Carlo simulation to assess parameter uncertainties in gallium supply and demand. The uncertainties of each parameter are graded as three levels: low, medium, and high, as shown in Table S11. Parameter data directly extracted from literature was assumed to be with low uncertainty. Parameter data calculated based on the literature was regarded with medium uncertainty, and those based on informed assumptions are set to be high uncertainty. We performed the Monte Carlo simulation by 10,000 times, assuming that uncertainties in parameters are described by a normal distribution with coefficients of variation $(\mathrm{CVs})(2 \%, 5 \%$, and $10 \%$ for the low, medium, and high levels) as most previous studies $\operatorname{did}^{44}$. The uncertainty results for the gallium supply under low production capacity scenario (S2) and gallium demand under APS (D2) are shown in Figure S16. 
Table S11 Parameter uncertainty for Monte Carlo simulation

\begin{tabular}{|c|c|c|c|c|c|c|c|c|}
\hline Parameters & Source & $\begin{array}{l}\text { Uncertainty } \\
\text { grade }\end{array}$ & CVs & $\begin{array}{l}\text { Mean } \\
\text { value }\end{array}$ & $\begin{array}{l}\text { Min. } \\
\text { value }\end{array}$ & $\begin{array}{l}\text { Max. } \\
\text { value }\end{array}$ & $\begin{array}{l}\text { Standard } \\
\text { Deviation }\end{array}$ & Distribution \\
\hline Aluminum production efficiency (\%) & 10 & Low & $2 \%$ & 50 & 49 & 51 & 1 & Random Normal \\
\hline Alumina production efficiency (\%) & 11 & Low & $2 \%$ & 40 & 39 & 41 & 0.8 & Random Normal \\
\hline Production rate of new aluminum scrap (\%) & 12 & Low & $2 \%$ & 7 & 6.86 & 7.14 & 0.14 & Random Normal \\
\hline Recovery coefficient of old aluminum scrap (\%) & 12 & Low & $2 \%$ & 70 & 68.6 & 71.4 & 1.4 & Random Normal \\
\hline Secondary aluminum production coefficient (\%) & 12 & Low & $2 \%$ & 83 & 81.34 & 84.66 & 1.66 & Random Normal \\
\hline $\begin{array}{l}\text { Sensitivity of aluminum price to supply and demand } \\
\text { balance }\end{array}$ & 1 & Low & $2 \%$ & 0.7 & 0.686 & 0.714 & 0.014 & Random Normal \\
\hline Aluminum price elasticity of demand & 13 & Low & $2 \%$ & 0.07 & 0.0686 & 0.0714 & 0.014 & Random Normal \\
\hline Impact factor of aluminum production cost on the price & 13 & Low & $2 \%$ & 0.6 & 0.588 & 0.612 & 0.012 & Random Normal \\
\hline Time to adjust aluminum price (year) & 1 & Low & $2 \%$ & 0.5 & 0.49 & 0.51 & 0.01 & Random Normal \\
\hline Average lifetime of aluminum products (year) & Calculated based on ${ }^{14,15}$ & Medium & $5 \%$ & 17 & 16.2 & 17.85 & 0.85 & Random Normal \\
\hline Growth rate of aluminum production cost (\%) & \multirow{2}{*}{$\begin{array}{c}\text { Assumption based on the } \\
\text { average inflation rate } \\
\text { from World Bank }\end{array}$} & Medium & $5 \%$ & 1 & 0.9 & 1.1 & 0.05 & Random Normal \\
\hline Growth rate of gallium production cost (\%) & & Medium & $5 \%$ & 1 & 0.9 & 1.1 & 0.05 & Random Normal \\
\hline Future China's net bauxite import (tons) & \multirow{5}{*}{$\begin{array}{c}\text { Assumption } \\
\text { based on historical trend }\end{array}$} & High & $10 \%$ & $9.06 \mathrm{e}+07$ & $1.11 \mathrm{e}+08$ & $1.01 \mathrm{e}+08$ & $1.01 \mathrm{e}+07$ & Random Normal \\
\hline Future primary aluminum net export in China (tons) & & High & $10 \%$ & 360418 & $3.24 \mathrm{e}+05$ & $3.96 \mathrm{e}+05$ & 36042 & Random Normal \\
\hline Future aluminum products net export in China (tons) & & High & $10 \%$ & $5.38 \mathrm{e}+06$ & $4.84 \mathrm{e}+06$ & $5.92 \mathrm{e}+06$ & $5.38 \mathrm{e}+05$ & Random Normal \\
\hline Future alumina net import in China (tons) & & High & $10 \%$ & $1.37 \mathrm{e}+06$ & $1.23 \mathrm{e}+06$ & $1.51 \mathrm{e}+06$ & $1.37 \mathrm{e}+05$ & Random Normal \\
\hline Future aluminum scrap import in China (tons) & & High & $10 \%$ & $1.56 \mathrm{e}+06$ & $1.41 \mathrm{e}+06$ & $1.72 \mathrm{e}+06$ & $1.56 \mathrm{e}+05$ & Random Normal \\
\hline Gallium mass fraction in bauxite in China (ppm) & $\begin{array}{l}\text { Following the } \\
\text { assumption from } \\
3,7\end{array}$ & High & $10 \%$ & 54 & 48.6 & 59.4 & 5.4 & Random Normal \\
\hline Gallium marginal profit $(\%)$ & Assumption based on ${ }^{4}$ & Medium & $5 \%$ & 5 & 4.8 & 5.25 & 0.25 & Random Normal \\
\hline primary gallium production capacity in the US (tons) & Assumption based on & High & $10 \%$ & 0 & 3 & 0 & 0.1 & Random Normal \\
\hline
\end{tabular}




\begin{tabular}{|c|c|c|c|c|c|c|c|c|}
\hline primary gallium production capacity in EU (tons) & \multirow{3}{*}{ historical trend } & High & $10 \%$ & 18 & 16.2 & 19.8 & 1.8 & Random Normal \\
\hline primary gallium production capacity in Japan (tons) & & High & $10 \%$ & 3 & 2.7 & 3.3 & 0.3 & Random Normal \\
\hline primary gallium production capacity in RoW (tons) & & High & $10 \%$ & 11 & 9.9 & 12.1 & 1.1 & Random Normal \\
\hline Recycling rate of GIGS production scrap (\%) & 7 & Low & $2 \%$ & 0.5 & 0 & 1 & 0.01 & Random Normal \\
\hline Recycling rate of GIGS fabrication scrap (\%) & 7 & Low & $2 \%$ & 56 & 55 & 57 & 1.12 & Random Normal \\
\hline Recycling rate of GaAs substrate production scrap (\%) & 7 & Low & $2 \%$ & 58 & 57 & 59 & 1.16 & Random Normal \\
\hline Recycling rate of GaAs substrate fabrication scrap (\%) & 7 & Low & $2 \%$ & 8 & 7.84 & 8.16 & 0.16 & Random Normal \\
\hline Recycling rate of GaP substrate production scrap (\%) & 7 & Low & $2 \%$ & 58 & 57 & 59 & 1.16 & Random Normal \\
\hline Recycling rate of GaP substrate fabrication scrap (\%) & 7 & Low & $2 \%$ & 24 & 23.52 & 24.48 & 0.48 & Random Normal \\
\hline Recycling rate for GaN LED production (\%) & 7,45 & Low & $2 \%$ & 0.5 & 0 & 1 & 0.01 & Random Normal \\
\hline Recycling rate for GaN LED fabrication scrap (\%) & 7,45 & Low & $2 \%$ & 24 & 23.52 & 24.48 & 0.48 & Random Normal \\
\hline Recycling rate of NdFeB magnets production scrap (\%) & 7 & Low & $2 \%$ & 0.5 & 0 & 1 & 0.01 & Random Normal \\
\hline Recycling rate of NdFeB magnets fabrication scrap (\%) & 7 & Low & $2 \%$ & 0.5 & 0 & 1 & 0.01 & Random Normal \\
\hline Price elasticity of gallium demand & by calculation & High & $10 \%$ & 0.2 & 0.18 & 0.22 & 0.02 & Random Normal \\
\hline $\begin{array}{l}\text { Sensitivity of gallium prices to supply and demand } \\
\text { balances }\end{array}$ & by calculation & High & $10 \%$ & 0.6 & 0.54 & 0.66 & 0.06 & Random Normal \\
\hline Time to adjust gallium price (year) & 1 & Low & $2 \%$ & 0.5 & 0.49 & 0.51 & 0.01 & Random Normal \\
\hline Impact factor of gallium production cost on price & 20 & Low & $2 \%$ & 0.6 & 0.588 & 0.612 & 0.012 & Random Normal \\
\hline GaAs/GaP-based LED market share (\%) & \multirow{2}{*}{$\begin{array}{l}\text { Following the } \\
\text { assumption from }{ }^{7}\end{array}$} & High & $10 \%$ & 30 & 27 & 33 & 3 & Random Normal \\
\hline GaN-based LED market share (\%) & & High & $10 \%$ & 70 & 63 & 77 & 7 & Random Normal \\
\hline Thickness of deposition layer of LED $(\mu \mathrm{m})$ & 7 & Low & $2 \%$ & 4 & 3.92 & 4.08 & 0.08 & Random Normal \\
\hline Thickness of GaP substrate $(\mu \mathrm{m})$ & 7 & Low & $2 \%$ & 562 & 551 & 573 & 112 & Random Normal \\
\hline Thickness of GaAs substrate $(\mu \mathrm{m})$ & 7 & Low & $2 \%$ & 653 & 640 & 666 & 130 & Random Normal \\
\hline Fabrication loss rate of LED (\%) & 7 & Low & $2 \%$ & 37 & 36 & 38 & 0.74 & Random Normal \\
\hline Production yield of GaP substrate (\%) & 7 & Low & $2 \%$ & 35 & 34 & 36 & 0.7 & Random Normal \\
\hline
\end{tabular}




\begin{tabular}{|c|c|c|c|c|c|c|c|c|}
\hline Production yield of GaAs substrate (\%) & 7 & Low & $2 \%$ & 35 & 34 & 36 & 0.7 & Random Normal \\
\hline Production yield of GaN LED compound (\%) & 7 & Low & $2 \%$ & 11 & 10.8 & 11.2 & 0.22 & Random Normal \\
\hline Gallium intensity in $\mathrm{GaP}\left(\mathrm{g} / \mathrm{cm}^{3}\right)$ & 7 & Low & $2 \%$ & 2.87 & 2.81 & 2.93 & 0.06 & Random Normal \\
\hline Gallium intensity in GaAs $\left(\mathrm{g} / \mathrm{cm}^{3}\right)$ & 7 & Low & $2 \%$ & 2.56 & 2.51 & 2.61 & 0.05 & Random Normal \\
\hline Gallium intensity in $\mathrm{GaN}\left(\mathrm{g} / \mathrm{cm}^{3}\right)$ & 7 & Low & $2 \%$ & 5.12 & 5.02 & 5.22 & 0.1 & Random Normal \\
\hline Thickness of IC chips $(\mu \mathrm{m})$ & 7 & Low & $2 \%$ & 100 & 98 & 102 & 2 & Random Normal \\
\hline Fabrication loss rate of GaAs IC (\%) & 7 & Low & $2 \%$ & 22 & 23.56 & 20.44 & 0.44 & Random Normal \\
\hline Deposition yield of CIGS (\%) & 7 & Low & $2 \%$ & 45 & 44 & 46 & 0.9 & Random Normal \\
\hline Fabrication loss rate of CIGS (\%) & 7 & Low & $2 \%$ & 8 & 7.8 & 8.16 & 0.16 & Random Normal \\
\hline Production yield of CIGS (\%) & 7 & Low & $2 \%$ & 100 & 98 & 100 & 2 & Random Normal \\
\hline Gallium intensity in NdFeB magnets (\%) & $\begin{array}{c}\text { Following the } \\
\text { assumption from }\end{array}$ & High & $10 \%$ & 0.5 & 0.45 & 0.55 & 0.05 & Random Normal \\
\hline Fabrication yield of $\mathrm{NdFeB}$ magnets $(\%)$ & 7 & Low & $2 \%$ & 70 & 68.6 & 71.4 & 1.4 & Random Normal \\
\hline Production yield of $\mathrm{NdFeB}$ magnets $(\%)$ & 7 & Low & $2 \%$ & 100 & 98 & 100 & 2 & Random Normal \\
\hline Gallium intensity in CIGS (kg/MW) & $7,21-27$ & Low & $2 \%$ & 5 & 4.9 & 5.1 & 1 & Random Normal \\
\hline Gallium intensity in BEV (g/unit) & $25,28,29$ & Low & $2 \%$ & 1.68 & 1.65 & 1.70 & 0.0336 & Random Normal \\
\hline Gallium intensity in PHEV (g/unit) & $25,28,29$ & Low & $2 \%$ & 1.05 & 1.029 & 1.07 & 0.021 & Random Normal \\
\hline Gallium intensity in wind turbine $(\mathrm{kg} / \mathrm{MW})$ & $7,9,23$ & Low & $2 \%$ & 2.8 & 2.74 & 2.86 & 0.056 & Random Normal \\
\hline
\end{tabular}



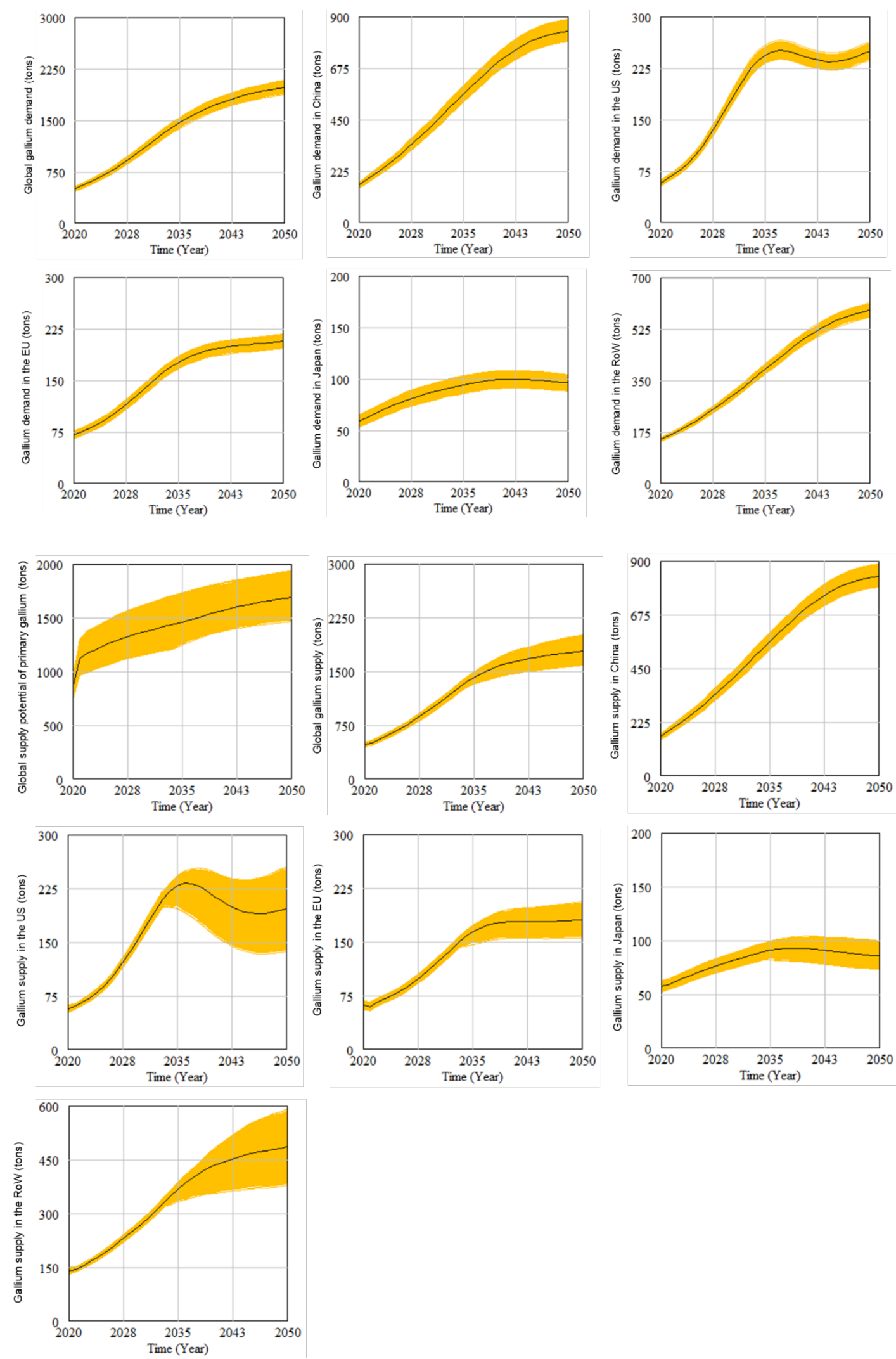

Figure S16. Uncertainty analysis results of gallium demand and supply. 


\section{Results and discussions}

\subsection{World and regional gallium supply and demand under different scenarios}
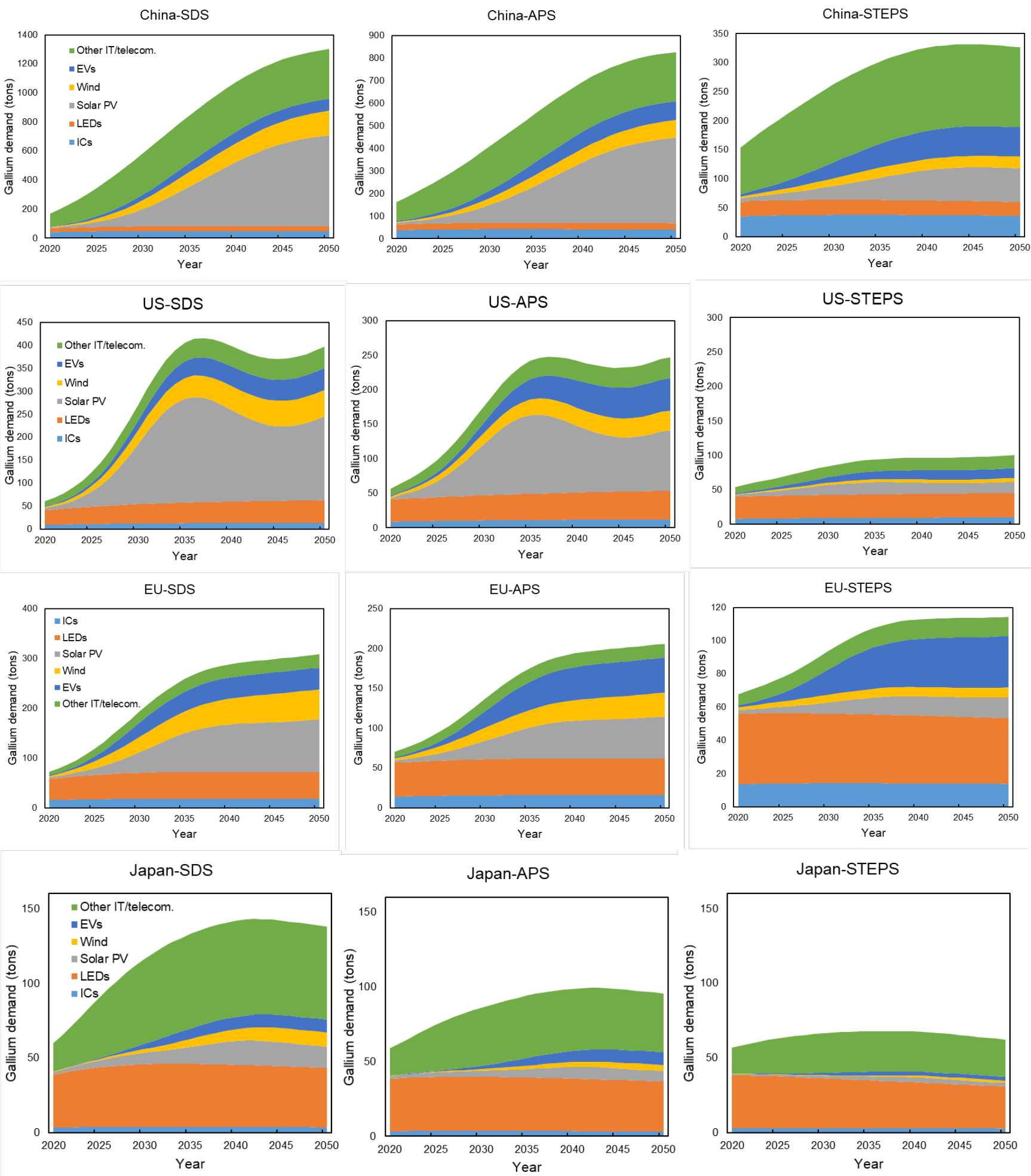

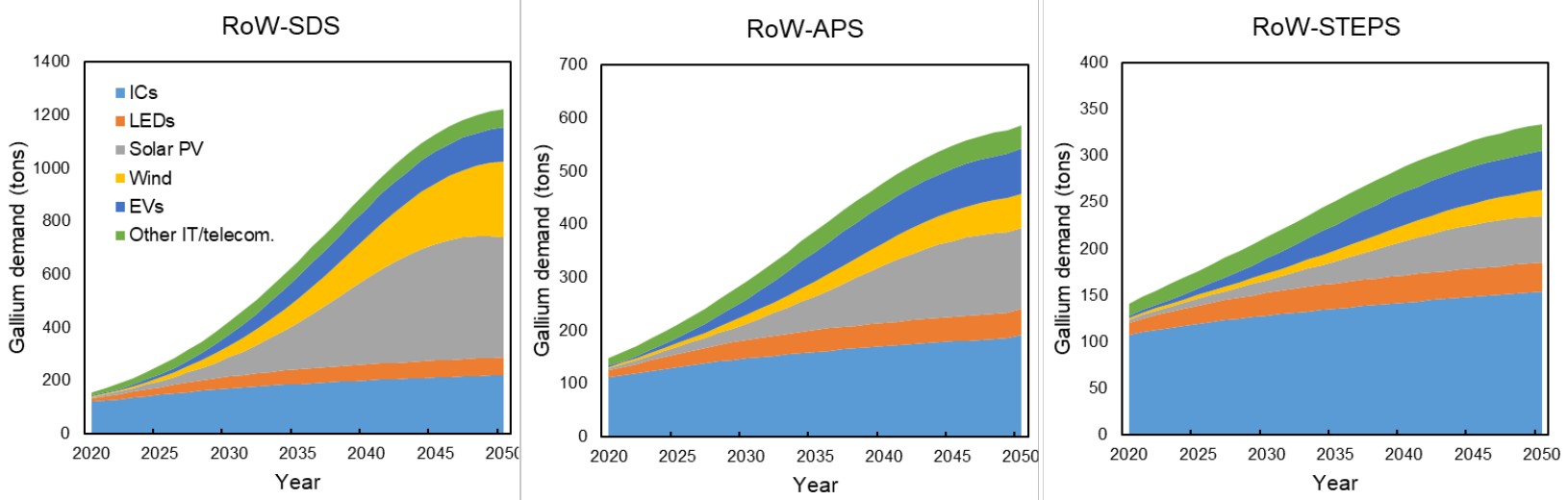

Figure S17. Regional gallium demand structure under different green transition scenarios
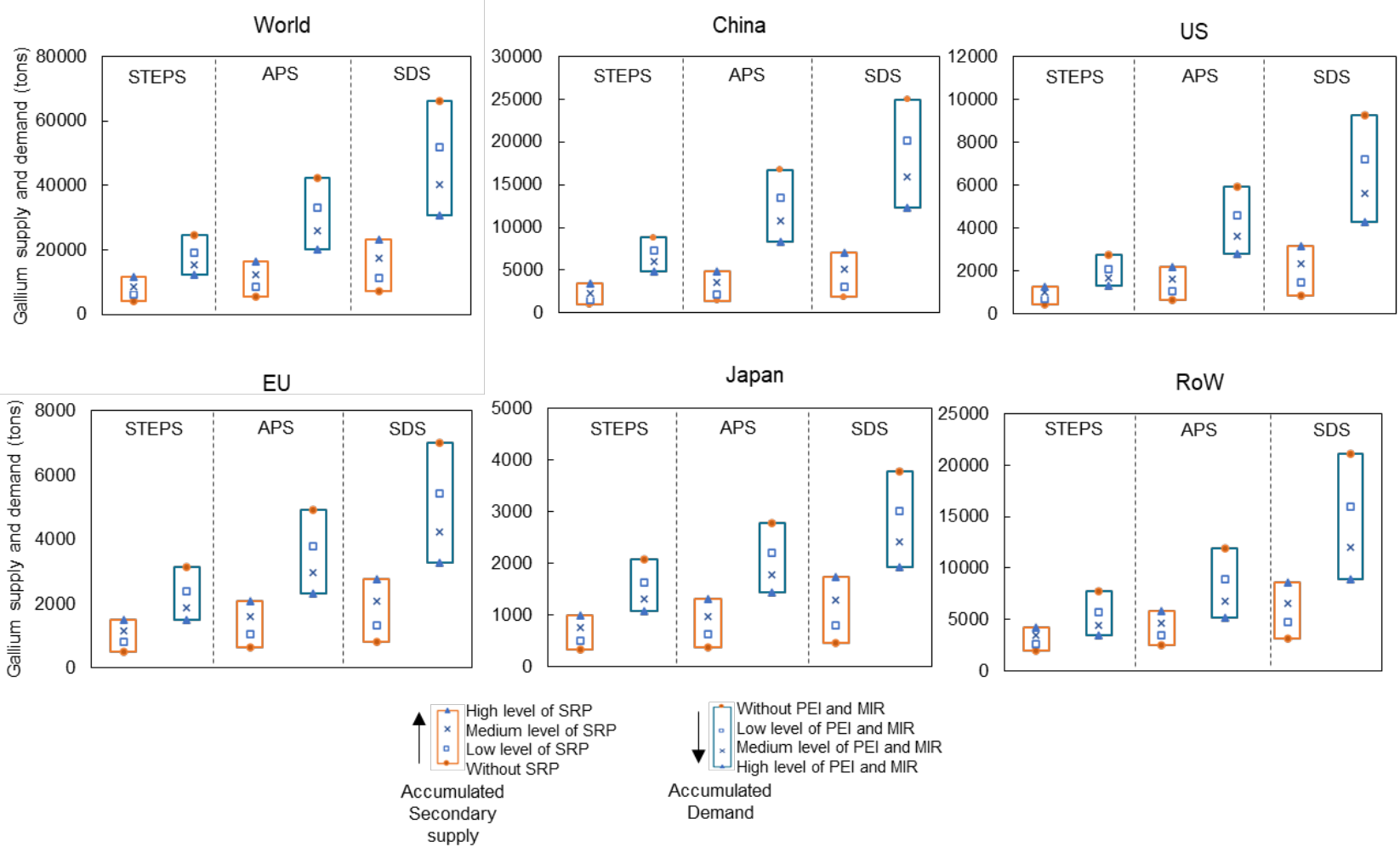

Figure S18. The global and regional increase of accumulated secondary gallium supply (with scrap recycling promotion, SRP) and decrease of accumulated gallium demand (with process efficiency improvement, PEI, and material intensity reduction, MIR) from 2019 to 2050 under different green transition scenarios.

\subsection{Comparison between integrated SD model and MFA model for gallium cycle}

To conduct a comparison of the result differences between the integrated SD model in our research and the MFA model developed by Løvik et al., ${ }^{7}$ the main parameters used in the two models are listed in Table S12. 
Table S12. Variables comparison between integrated SD model and MFA model

\begin{tabular}{|c|c|c|c|}
\hline \multicolumn{2}{|r|}{ Variable } & $\begin{array}{l}\text { Integrated SD model } \\
\text { in this research }\end{array}$ & $\begin{array}{l}\text { MFA model in } \\
\text { Løvik's research }\end{array}$ \\
\hline \multirow{5}{*}{ Aluminum } & Aluminum in use stock saturation level & $\sqrt{ }$ (in China) & $\sqrt{ }$ (in the world) \\
\hline & Bauxite production & $\sqrt{\text { (in China) }}$ & $\sqrt{ }$ (in the world) \\
\hline & $\begin{array}{l}\text { Impact of aluminum supply and demand balance on } \\
\text { price }\end{array}$ & $\sqrt{ }$ & $x$ \\
\hline & Aluminum price & $\sqrt{ }$ & $\times$ \\
\hline & Aluminum production cost & $\sqrt{ }$ & $x$ \\
\hline \multirow{7}{*}{$\begin{array}{l}\text { Gallium } \\
\text { supply }\end{array}$} & Gallium mass fraction in bauxite & $\sqrt{ }$ & $\sqrt{ }$ \\
\hline & Rate of bauxite used for gallium extraction & $\sqrt{ }$ & $\sqrt{ }$ \\
\hline & Gallium recovery rate from bauxite & $\begin{array}{l}\sqrt{\text { Changing with the }} \\
\text { gallium price system }\end{array}$ & $\begin{array}{l}\times \text { Constant } \\
\text { assumption }\end{array}$ \\
\hline & Gallium net import or export & $\sqrt{ }$ (in each region) & $\times$ \\
\hline & Regional gallium supply & $\sqrt{ }$ (in five region) & $\times($ in the world $)$ \\
\hline & Recycling rate of gallium new scrap & $\sqrt{ }$ & $\sqrt{ }$ \\
\hline & Recycling rate of gallium old scrap & $\sqrt{ }$ (in each region) & $\sqrt{ }$ (in the world) \\
\hline \multirow{5}{*}{$\begin{array}{l}\text { Gallium } \\
\text { price }\end{array}$} & Gallium price & $\sqrt{ }$ & $\times$ \\
\hline & Price elasticity of gallium demand & $\sqrt{ }$ & $x$ \\
\hline & Sensitivity of Ga prices to supply and demand balance & $\sqrt{ }$ & $\times$ \\
\hline & Impact factor of gallium production cost on price & $\sqrt{ }$ & $\times$ \\
\hline & Impact of gallium price on aluminum production cost & $\sqrt{ }$ & $\times$ \\
\hline \multirow{11}{*}{$\begin{array}{l}\text { Gallium } \\
\text { demand } \\
\text { for LED }\end{array}$} & LED market penetration rate & $\sqrt{ }$ (in each region) & $\sqrt{ }$ (in the world) \\
\hline & GaAs/ GaN-based LED market share & $\sqrt{ }$ & $\sqrt{ }$ \\
\hline & GaN-based LED market share & $\sqrt{ }$ & $\sqrt{ }$ \\
\hline & Share of GaAs/GaP LED fabricated on GaAs & $\sqrt{ }$ & $\sqrt{ }$ \\
\hline & Thickness of LED chips & $\sqrt{ }$ & $\sqrt{ }$ \\
\hline & Thickness of deposition layer of LED & $\sqrt{ }$ & $\sqrt{ }$ \\
\hline & Thickness of GaAs/GaP substrate & $\sqrt{ }$ & $\sqrt{ }$ \\
\hline & Fabrication loss rate of LED & $\sqrt{ }$ & $\sqrt{ }$ \\
\hline & Production yield of GaAs/GaP substrate & $\sqrt{ }$ & $\sqrt{ }$ \\
\hline & Production yield of GaN LED compound & $\sqrt{ }$ & $\sqrt{ }$ \\
\hline & Gallium intensity in GaAs/GaP / GaN/ AlinGaP & $\sqrt{ }$ & $\sqrt{ }$ \\
\hline \multirow{4}{*}{$\begin{array}{c}\text { Gallium } \\
\text { demand } \\
\text { for IC }\end{array}$} & Mobile phone sales & $\sqrt{ }$ (in each region) & $\sqrt{ }$ (in the world) \\
\hline & The area of GaAs chips per phone & $\sqrt{ }$ & $\sqrt{ }$ \\
\hline & Thickness of IC chips & $\sqrt{ }$ & $\sqrt{ }$ \\
\hline & Fabrication loss rate of GaAs IC & $\sqrt{ }$ & $\sqrt{ }$ \\
\hline
\end{tabular}




\begin{tabular}{|c|c|c|c|}
\hline \multirow{6}{*}{$\begin{array}{l}\text { Gallium } \\
\text { demand } \\
\text { for CIGS }\end{array}$} & solar PV installed capacity & $\sqrt{ }$ (in each region) & $\sqrt{ }$ (in the world) \\
\hline & Market share of CIGS in solar PV & $\sqrt{ }($ in each region) & $\sqrt{ }$ (in the world) \\
\hline & Gallium intensity in CIGS & $\sqrt{ }$ & $\sqrt{ }$ \\
\hline & Deposition yield of CIGS & $\sqrt{ }$ & $\sqrt{ }$ \\
\hline & Fabrication loss rate of CIGS & $\sqrt{ }$ & $\sqrt{ }$ \\
\hline & Production yield of CIGS & $\sqrt{ }$ & $\sqrt{ }$ \\
\hline \multirow{12}{*}{$\begin{array}{c}\text { Gallium } \\
\text { demand } \\
\text { for } \mathrm{NdFeB} \\
\text { magnets }\end{array}$} & Passenger car sales & $\sqrt{ }$ (in each region) & $\sqrt{ }$ (in the world) \\
\hline & wind power installed capacity & $\sqrt{ }$ (in each region) & $\sqrt{ }$ (in the world) \\
\hline & EV market share & $\sqrt{ }$ (in each region) & $\sqrt{ }$ (in the world) \\
\hline & BEV market share & $\sqrt{ }$ & $x$ \\
\hline & PHEV market share & $\sqrt{ }$ & $x$ \\
\hline & Market share of direct drive wind turbines & $\sqrt{ }$ (in each region) & $\sqrt{ }$ (in the world) \\
\hline & Share of NdFeB magnets using gallium & $\sqrt{ }$ & $\sqrt{ }$ \\
\hline & Gallium intensity in EV & $\sqrt{ }$ (in BEV and PHEV) & $\sqrt{ }$ \\
\hline & Gallium intensity in wind turbine & $\sqrt{ }$ & $\sqrt{ }$ \\
\hline & Gallium intensity in NdFeB magnets & $\sqrt{ }$ & $\sqrt{ }$ \\
\hline & Fabrication yield of NdFeB magnets & $\sqrt{ }$ & $\sqrt{ }$ \\
\hline & Production yield of $\mathrm{NdFeB}$ magnets & $\sqrt{ }$ & $\sqrt{ }$ \\
\hline
\end{tabular}

Both models considered the supply linkage between aluminum and gallium, and different saturation levels of aluminum in use stock were involved in the supply scenarios. Unlike estimating the global gallium supply as a whole like in Løvik et al., the uneven distribution of the gallium resources in different regions is considered in our SD model. As China plays a dominant role in the global gallium production, the byproduct relationship between aluminum and gallium in China was revealed clearly in the SD model. The gallium trade system in the studied five regions has been also considered in our SD model. Moreover, unlike Løvik et al., who assumed the gallium recovery rate constant in estimating the gallium supply potential, the feedback between gallium price and gallium recovery rate from bauxite is included in our SD model by incorporating the byproduct availability curves from Frenzel et al. ${ }^{3}$, which could reveal the dynamics of gallium supply potential influenced by the gallium demand and price.

Compared to the global demand estimation of gallium by Løvik et al., our research aimed to furtherly explore the regional difference of gallium demand. Thus, the final gallium applications demand and market shares of emerging technologies using gallium were set for those studied regions based on their market conditions. The global gallium demand will reach 938 tons/year by 2050 under the STEPS scenario in our model, which is close to that under the business-as-usual scenario 
considered in the research by Løvik et al. The gallium demand under the SDS is 3367 tons/year by 2050 in our study, which is lower than the highest gallium demand of 5200 tons/year projected by Løvik et al. This is because ambitious goals were set in the referred study for the global market share of CIGS (40\%) in the solar PV technologies and the share of $\mathrm{NdFeB}$ magnets containing gallium (90\%). This also indicates the high uncertainty in the future development of emerging energy technologies.

To simulate the impacts of the ignored gallium price system on the estimation of the gallium supply potential estimation in the referred MFA model, we put the same parametric values from Lovik et al. into our SD modelling, and compared the result differences caused by the modeling choices. Many scenarios for gallium supply and demand had been set in the research of Lovik et al., and we selected those scenarios representing relatively low supply and high demand levels of gallium into our SD model, as shown in Table S13.

Specifically, the same parametric values for the low supply scenario of "African bauxite" and high demand scenario of "clean energy with gallium" from Lovik et al. (2016) were put into our SD model. And the estimated gallium supply potential and demand by our model are shown in Figure S19. The results from Lovik et al. (2016) showed a gallium shortage risk under both of these two scenarios, with a supply potential of 1800 tons/year and a gallium demand of 5200 tons/year in 2050. However, the estimated gallium supply potential from our model reaches 4773 tons/year in 2050, which could satisfy the gallium demand of 4633 tons/year, as shown in Figure S19. The reason for the higher supply potential in our results is that despite of the low saturation level of aluminum stock, growing gallium price under the high demand scenario could drive the gallium recovery rate (from bauxite) increase to $62 \%$ by 2050 . Moreover, the high gallium demand could also be reduced by the growth of gallium price due to the price elasticity of demand. This indicated the significant role of the price mechanism in the dynamics of gallium supply and demand systems.

Table S13. Scenario selections for modelling comparison from the research of Lovik et al.

\begin{tabular}{|c|c|c|}
\hline \multicolumn{2}{|c|}{ Scenario name } & Parameter assumptions in Lovik et al. \\
\hline $\begin{array}{l}\text { Gallium } \\
\text { supply }\end{array}$ & $\begin{array}{l}\text { "African } \\
\text { bauxite" }\end{array}$ & $\begin{array}{l}\text { Aluminum recycling: business as usual } \\
\text { Aluminum stock saturation level: } 200 \mathrm{~kg} / \text { capita } \\
\text { Gallium mass fraction in bauxite in } 2050: 43 \mathrm{ppm}\end{array}$ \\
\hline $\begin{array}{l}\text { Gallium } \\
\text { demand }\end{array}$ & $\begin{array}{l}\text { "Clean energy } \\
\text { with gallium" }\end{array}$ & $\begin{array}{l}\text { Market share of CIGS in PV market in } 2050: 40 \% \\
\text { share of NdFeB magnets containing Gallium in } \\
\text { 2050: } 100 \% \\
\text { Magnet and PV demand based on IEA 2DS-high } \\
\text { renewables }\end{array}$ \\
\hline
\end{tabular}




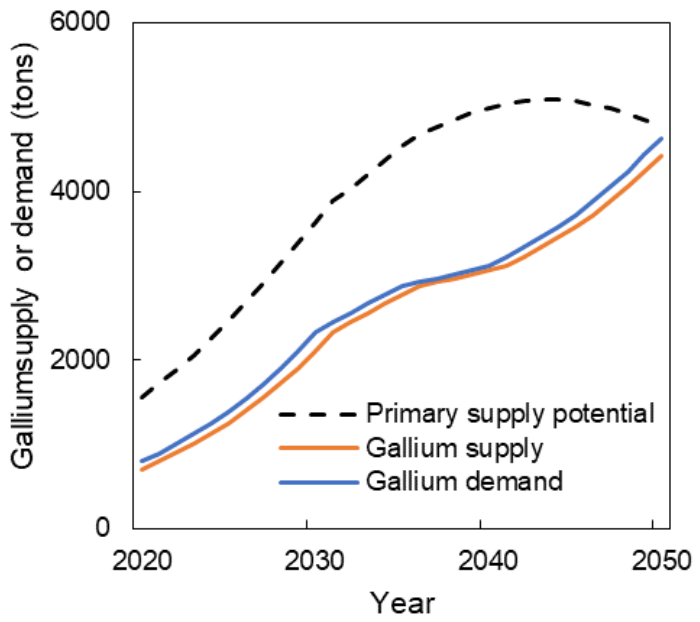

Figure S19. Estimated gallium supply and demand by SD model under the scenarios of Lovik et al. ${ }^{7}$

\section{References}

(1) Choi, C. H.; Cao, J.; Zhao, F. System Dynamics Modeling of Indium Material Flows under Wide Deployment of Clean Energy Technologies. Resour. Conserv. Recycl. 2016, 114, 5971.

(2) World Bank. Global Economic Propects - Having Fiscal Space and Using It. World Bank Group. 2015.

(3) Frenzel, M.; Ketris, M. P.; Seifert, T.; Gutzmer, J. On the Current and Future Availability of Gallium. Resour. Policy 2016, 47, 38-50.

(4) National Bureau of Statistics of China. China Statistical Yearbook 2020; 2020.

(5) Licht, C.; Peiró, L. T.; Villalba, G. Global Substance Flow Analysis of Gallium, Germanium, and Indium: Quantification of Extraction, Uses, and Dissipative Losses within Their Anthropogenic Cycles. J. Ind. Ecol. 2015, 19 (5), 890-903.

(6) United Nations. World Population Prospects 2019; 2019.

(7) Løvik, A. N.; Restrepo, E.; Müller, D. B. Byproduct Metal Availability Constrained by Dynamics of Carrier Metal Cycle: The Gallium-Aluminum Example. Environ. Sci. Technol. 2016, 50, 8453-8461.

(8) IEA. World Energy Outlook 2021; 2021.

(9) Habib, K.; Wenzel, H. Exploring Rare Earths Supply Constraints for the Emerging Clean 
Energy Technologies and the Role of Recycling. J. Clean. Prod. 2014, 84, 348-359.

(10) Sverdrup, H. U.; Ragnarsdottir, K. V.; Koca, D. Aluminium for the Future: Modelling the Global Production, Market Supply, Demand, Price and Long Term Development of the Global Reserves. Resour. Conserv. Recycl. 2015, 103, 139-154.

(11) Liu, G.; Müller, D. B. Centennial Evolution of Aluminum In-Use Stocks on Our Aluminized Planet. Environ. Sci. Technol. 2013, 47, 4882-4888.

(12) Li, Y.; Yue, Q.; He, J.; Zhao, F.; Wang, H. When Will the Arrival of China's Secondary Aluminum Era? Resour. Policy 2020, 65, 101573.

(13) Stuermer, M. Industrialization and the Demand for Mineral Commodities. J. Int. Money Financ. 2017, 76, 16-27.

(14) Li, Q.; Zhang, W.; Li, H.; He, P. CO2 Emission Trends of China's Primary Aluminum Industry: A Scenario Analysis Using System Dynamics Model. Energy Policy 2017, 105, $225-235$.

(15) Dai, M.; Wang, P.; Chen, W. Q.; Liu, G. Scenario Analysis of China's Aluminum Cycle Reveals the Coming Scrap Age and the End of Primary Aluminum Boom. J. Clean. Prod. 2019, 226, 793-804.

(16) CM Group. An Initial Assessment of the Impact of COVID-19 Pandemic on Global Aluminium Demand; 2020.

(17) The Japan Oil, G. and M. N. C. 鉱物資源 マテリアルフロー 2018; 2018.

(18) U.S. Geological Survey. Mineral Commodity Summaries 2021; 2021.

(19) U.S. Geological Survey. 2018 Minerals Yearbook: Gallium; 2021.

(20) Shao, L.; Jin, S. Resilience Assessment of the Lithium Supply Chain in China under Impact of New Energy Vehicles and Supply Interruption. J. Clean. Prod. 2020, 252, 119624.

(21) Watari, T.; McLellan, B. C.; Ogata, S.; Tezuka, T. Analysis of Potential for Critical Metal Resource Constraints in the International Energy Agency's Long-Term Low-Carbon Energy Scenarios. Minerals 2018, 8 (4), 156.

(22) Carrara, S.; Alves Dias, P.; Plazzotta, B.; Pavel, C. Raw Materials Demand for Wind and Solar PV Technologies in the Transition towards a Decarbonised Energy System. Eur. 
Comm. 2020, 1-74.

(23) Elshkaki, A.; Shen, L. Energy-Material Nexus: The Impacts of National and International Energy Scenarios on Critical Metals Use in China up to 2050 and Their Global Implications. Energy 2019, 180, 903-917.

(24) Nassar, N. T.; Wilburn, D. R.; Goonan, T. G. Byproduct Metal Requirements for U.S. Wind and Solar Photovoltaic Electricity Generation up to the Year 2040 under Various Clean Power Plan Scenarios. Appl. Energy 2016, 183, 1209-1226.

(25) Valero, A.; Valero, A.; Calvo, G.; Ortego, A. Material Bottlenecks in the Future Development of Green Technologies. Renew. Sustain. Energy Rev. 2018, 93, 178-200.

(26) Elshkaki, A.; Graedel, T. E. Dynamic Analysis of the Global Metals Flows and Stocks in Electricity Generation Technologies. J. Clean. Prod. 2013, 59, 260-273.

(27) Kavlak, G.; McNerney, J.; Jaffe, R. L.; Trancik, J. E. Metal Production Requirements for Rapid Photovoltaics Deployment. Energy Environ. Sci. 2015.

(28) Valero, A.; Valero, A.; Calvo, G.; Ortego, A.; Ascaso, S.; Palacios, J. L. Global Material Requirements for the Energy Transition. An Exergy Flow Analysis of Decarbonisation Pathways. Energy 2018, 159, 1175-1184.

(29) Grandell, L.; Lehtilä, A.; Kivinen, M.; Koljonen, T.; Kihlman, S.; Lauri, L. S. Role of Critical Metals in the Future Markets of Clean Energy Technologies. Renew. Energy 2016, $95,53-62$.

(30) Wu, Y.; Yang, L.; Tian, X.; Li, Y.; Zuo, T. Temporal and Spatial Analysis for End-of-Life Power Batteries from Electric Vehicles in China. Resour. Conserv. Recycl. 2020, 155, 104651.

(31) He, P.; Wang, C.; Zuo, L. The Present and Future Availability of High-Tech Minerals in Waste Mobile Phones: Evidence from China. J. Clean. Prod. 2018, 192, 940-949.

(32) Månberger, A.; Stenqvist, B. Global Metal Flows in the Renewable Energy Transition: Exploring the Effects of Substitutes, Technological Mix and Development. Energy Policy 2018, 119, 226-241.

(33) Stamp, A.; Wäger, P. A.; Hellweg, S. Linking Energy Scenarios with Metal Demand Modeling-The Case of Indium in CIGS Solar Cells. Resour. Conserv. Recycl. 2014, 93, 156- 
167.

(34) Deng, X.; Ge, J. Global Wind Power Development Leads to High Demand for Neodymium Praseodymium (NdPr): A Scenario Analysis Based on Market and Technology Development from 2019 to 2040. J. Clean. Prod. 2020, 277, 123299.

(35) Wang, P.; Chen, L. Y.; Ge, J. P.; Cai, W.; Chen, W. Q. Incorporating Critical Material Cycles into Metal-Energy Nexus of China's 2050 Renewable Transition. Appl. Energy 2019, 253,113612 .

(36) Viebahn, P.; Soukup, O.; Samadi, S.; Teubler, J.; Wiesen, K.; Ritthoff, M. Assessing the Need for Critical Minerals to Shift the German Energy System towards a High Proportion of Renewables. Renew. Sustain. Energy Rev. 2015, 49, 655-671.

(37) IEA. Global EV Outlook 2021; 2021.

(38) General Office of the State Council of China. New Energy Automobile Industry Plan in China (2021-2035); 2020.

(39) IEA. An Energy Sector Roadmap to Carbon Neutrality in China; 2021.

(40) European Commission. Communication from the Commission on the EU Strategy for a Sustainable and Smart Mobility, Brussels 2020. 2020, 4.

(41) European Commission. The European Green Deal; 2019.

(42) METI Ministry of Economy, T. and I. Japan's 2050 Carbon Neutral Goal; 2021.

(43) Zissis, G.; Bertoldi, P. Status of LED-Lighting World Market in 2017. Jt. Res. Cent. 2018.

(44) Liu, Q.; Cao, Z.; Liu, X.; Liu, L.; Dai, T.; Han, J.; Duan, H.; Wang, C.; Wang, H.; Liu, J.; Cai, G.; Mao, R.; Wang, G.; Tan, J.; Li, S.; Liu, G. Product and Metal Stocks Accumulation of China's Megacities: Patterns, Drivers, and Implications. Environ. Sci. Technol. 2019, 53 (8), 4128-4139.

(45) Eheliyagoda, D.; Zeng, X.; Wang, Z.; Albalghiti, E.; Li, J. Forecasting the Temporal Stock Generation and Recycling Potential of Metals towards a Sustainable Future: The Case of Gallium in China. Sci. Total Environ. 2019, 689, 332-340. 